\title{
Support-free nanostructured Pt Cu electrocatalyst for the oxygen reduction reaction prepared by alternating magnetron sputtering
}

\author{
Sievers, Gustav Wilhelm; Bowen, Jacob R.; Brüser, Volker; Arenz, Matthias
}

Published in:

Journal of Power Sources

Link to article, DOI:

10.1016/j.jpowsour.2018.12.044

Publication date:

2019

Document Version

Peer reviewed version

Link back to DTU Orbit

Citation (APA):

Sievers, G. W., Bowen, J. R., Brüser, V., \& Arenz, M. (2019). Support-free nanostructured Pt Cu electrocatalyst for the oxygen reduction reaction prepared by alternating magnetron sputtering. Journal of Power Sources, 413, 432-440. https://doi.org/10.1016/j.jpowsour.2018.12.044

\section{General rights}

Copyright and moral rights for the publications made accessible in the public portal are retained by the authors and/or other copyright owners and it is a condition of accessing publications that users recognise and abide by the legal requirements associated with these rights.

- Users may download and print one copy of any publication from the public portal for the purpose of private study or research.

- You may not further distribute the material or use it for any profit-making activity or commercial gain

- You may freely distribute the URL identifying the publication in the public portal 
Support-free nanostructured $\mathrm{Pt}-\mathrm{Cu}$ electrocatalyst for the oxygen reduction reaction prepared by alternating magnetron sputtering

Gustav Sievers ${ }^{\mathrm{a}, \mathrm{c},}{ }^{*}$, Jacob R. Bowen ${ }^{\mathrm{b}}$, Volker Brüser ${ }^{\mathrm{c}}$, Matthias Arenz ${ }^{\mathrm{d}}$

aUniversity of Copenhagen, Universitetsparken 5, 2100 Copenhagen

${ }^{\mathrm{b}}$ Department of Energy Conversion and Storage, Technical University of Denmark, Frederiksborgvej 399, 4000 Roskilde, Denmark

'Leibniz Institute for Plasma Science and Technology, Felix-Hausdorff-Strasse 2, 17489 Greifswald

${ }^{\mathrm{d} D e p a r t m e n t}$ of Chemistry and Biochemistry, University of Bern, Freiestrasse 3, CH-3012 Bern, Switzerland

*corresponding authors: gustav.sievers@chem.ku.dk; matthias.arenz@dcb.unibe.ch

Abstract

Nanostructuring of electrocatalysts is an important aspect of catalyst design as catalytic performance depends not only on the specific activity (reaction rate per surface area), but also on the dispersion of the catalyst. We present an industrially compatible, but effective preparation method for support-free nanostructured catalyst layers. Alternating sputtering was used to prepare heterogeneous Pt-Cu templates ranging from 95 up to 99.5 at. \% Cu. These templates were then electrochemically leached to form a nanostructured Pt-Cu network and benchmarked with respect to the oxygen reduction reaction. It is shown that the templates with lower $\mathrm{Cu}$ :Pt ratios exhibit the highest initial specific activity but have a relatively low electrochemically active surface area. Subjecting the samples to extended accelerated stress tests, it is found that the support-free nanostructured Pt-Cu networks are relatively resistant to high potential cycling, which can be explained by the lack of carbon corrosion. The loss in electrochemical surface area thereby depends on the initial Pt content. The specific oxygen reduction activity, however, approaches the value of bulk Pt. Although this decrease is not desirable, 
still an (specific) activity improvement of two to four times as compared carbon supported nanoparticles can be preserved.

Keywords: Oxygen reduction reaction; nanostructured catalysts; fuel cells; dealloying; Platinum; magnetron sputtering

\section{Introduction}

Electrocatalysts for the oxygen reduction reaction (ORR) are an essential part in proton exchange membrane fuel cells (PEMFCs). Current ORR catalysts contain a significant amount of precious metal and exhibit a high overpotential [1]. In the quest for improved ORR catalysts the main goals are to increase the precious metal related mass activity (MA), which determines the amount of precious metal needed for a specific power density as well as the stability. The MA is a combination of the surface related specific activity (SA) and the electrochemically active surface area (ECSA) of the catalyst. The most common strategies to enhance the MA are either focussed on increasing the SA or the ECSA. The increase in SA is often related to the alloying of Pt to utilize strain and ligand effects [2], which in general leads to a decrease in ECSA. The latter has severe consequences at higher current densities as the ORR becomes mass transport and not kinetically controlled $[2,3]$. Increasing the ECSA by comparison is achieved by dispersing small Pt or Pt-alloy nanoparticles onto a high surface area carbon support. This approach comes with the draw-back of the so-called particle-size effect of the ORR [4]. Depending on different data, the particle-size effect is held accountable for a 50 to $75 \%$ loss of SA $[5,6]$, thus limiting the mass activity. Furthermore, if the particles become too small, their longterm stability is limited. Another source of degradation is corrosion of the carbon support, which can lead to different degradation channels, in particular particle loss [7].

An alternative to the use of carbon supported nanoparticles with a very high surface-to-volume ratio are unsupported, porous electrocatalysts. The advantage of unsupported catalysts is that they behave like bulk Pt films, thus exhibiting a higher specific activity[6], i.e. not only that the carbon support 
corrosion becomes alleviated, but that the negative particle size effect of the ORR can be avoided. However, it has to be mentioned in the special case of low loaded unsupported Pt electrodes the specific activity can be decreased[8]. The prerequisite for the development of unsupported ORR catalysts, however, is a suitable nanostructuring approach that enables nanostructured films with high ECSA.

There are several techniques to produce nanostructures. Nanocasting with templates as micelles of amphiphilic polymer molecules or silica hard templates and nanostructuring by dealloying alloys are widely used [9]. Dealloying is normally used with homogenous alloyed and crystalline materials. The process of dealloying uses self-diffusion of ad-atoms, which results in a nanoporous material[10]. Heterogeneous materials can also be used and the resulting structure is dependent on the template structure in pore size and ligament size [11].

Several different supported and support-free nano- and mesostructured materials have been tested as potential ORR electrodes: Mesostructured thin films [12,13], nanowires [14], nanoframes [15] are the most promising with the nanowires achieving highest mass activities, but might be difficult to scaleup. Here we present an alternative approach to produce support-free nanostructured Pt-Cu networks via alternating sputtering of Pt and Cu layers as template followed by a dealloying process. It is shown that the $\mathrm{Pt}-\mathrm{Cu}$ templates obtained from the sputtering are heterogeneous and amorphous. The electrochemical leaching results in nanostructured films that became crystalline and exhibit favourable ORR performance compared to Pt/C standard catalysts.

\section{Experimental Section}

2.1 Sample preparation. Glassy carbon electrodes ( $5 \mathrm{~mm}$ diameter, HTW, Germany) were polished and ultrasonically cleaned in acetone, isopropanol, ethanol and ultrapure $\mathrm{H}_{2} \mathrm{O}$ (Millipore $18.2 \mathrm{M} \Omega \mathrm{cm}$ resistance and $2 \mathrm{ppb}$ TOC - Total Organic Content). The electrodes were thereafter transferred to a vacuum chamber and for 3 minutes plasma-activated at a pressure of $20 \mathrm{~Pa}$ in $\mathrm{O}_{2}$ atmosphere and a radio frequency (RF) power of $300 \mathrm{~W}$. Samples were then transferred to the deposition chamber 
(Neoplas $\mathrm{GmbH}$, Germany). To prepare the Pt-Cu templates, the reactor chamber was evacuated to a base pressure of $5 \cdot 10^{-3} \mathrm{~Pa}$. An argon plasma was ignited in the chamber at a working pressure of $5 \mathrm{~Pa}$. First a $15 \mathrm{~nm} \mathrm{Ti} \mathrm{(99.9 \%} \mathrm{Mateck} \mathrm{GmbH,} \mathrm{Germany)} \mathrm{interlayer} \mathrm{was} \mathrm{deposited} \mathrm{onto} \mathrm{the} \mathrm{glassy} \mathrm{carbon} \mathrm{by}$ magnetron sputtering[16]. For the Pt-Cu film deposition two magnetrons were equipped with planar targets of Cu (99.95 \%, Evotec GmbH, Germany) and Pt (99.95 \%, Junker Edelmetalle, Germany). They were located at the superior part of the recipient. The RF generators (Advanced Energy) had a driving frequency of $13.56 \mathrm{MHz}$. The recipient was configured in a way that the substrate holder is turned automatically towards the respective magnetron with the sputtering being initiated when the sample is in position below the magnetron. The RF power was chosen as $25 \mathrm{~W}$ for $\mathrm{Cu}$ and $15 \mathrm{~W}$ for Pt. The alternating sputtering process was repeated 11 times so that the total Pt loading of the as deposited electrode was $17 \mu \mathrm{g}_{\mathrm{Pt}} \mathrm{cm}^{-2}$ geo. We varied the deposition time of $\mathrm{Cu}$ to obtain different composition as $\mathrm{Pt}_{x} \mathrm{Cu}_{100-x}$ for $\mathrm{x}=0.5,1,2,3,5$, i.e. $\mathrm{Pt}_{5} \mathrm{Cu}_{95}, \mathrm{Pt}_{3} \mathrm{Cu}_{97}, \mathrm{Pt}_{2} \mathrm{Cu}_{98}, \mathrm{Pt}_{1} \mathrm{Cu}_{99}$ and $\mathrm{Pt}_{0.5} \mathrm{Cu}_{99.5}$. After deposition of these Pt-Cu templates, the glassy carbon electrode was inserted into a Teflon holder. Then samples were electrochemically leached, thereafter called leaching, by cycling them between $0.05 V_{\text {RHE }}$ and 1.1 $V_{\mathrm{RHE}}$ with a scan rate of $50 \mathrm{mV} \mathrm{s}^{-1}$, directly after immersion into a de-aerated $0.1 \mathrm{M} \mathrm{HClO}_{4}$ aqueous electrolyte until a stable cyclic voltammogram (CV) was achieved. This was typically the case after 40 potential cycles. As a control, the Pt and Cu content of the metal films were determined by energy dispersive X-ray spectroscopy (EDS) before leaching and after electrochemical testing. After leaching the $\mathrm{Cu}$ in the $0.1 \mathrm{M} \mathrm{HClO}_{4}$ electrolyte was replaced with clean $0.1 \mathrm{M} \mathrm{HClO}_{4}$.

2.2 Electrochemical characterisation. The electrode tips were mounted as working electrodes into a rotating disk electrode setup and placed in a separate three-compartment electrochemical Teflon cell. The reference electrode was separated by a Nafion Membrane from the working electrode [17]. All measurements were performed at room temperature using a NordicElectrochemistry ECi 200 potentiostat, a saturated Calomel reference electrode and a carbon rod as the counter electrode. Prior to each experiment the potential was calibrated to the reversible hydrogen potential (RHE) by bubbling $\mathrm{H}_{2}$ at the Pt working electrode and recording a polarization curve under rotation. The solution 
resistance was electronically compensated by a positive feedback scheme of the potentiostat; the effective iR drop was monitored online during the measurements. The potentials in this study are given with respect to the RHE. $0.1 \mathrm{M} \mathrm{HClO}_{4}$ aqueous solution was used as the electrolyte in all measurements. The electrolytes were made from MilliQ water (> $18.2 \mathrm{M} \Omega \mathrm{cm}$ ) and ultrapure concentrated $\mathrm{HClO}_{4}$ (Suprapur, Merck). The specific ORR activity (SA) was defined as the quotient of the kinetic current at a potential of $0.9 \mathrm{~V}_{\mathrm{RHE}}$ as calculated by the Koutecky-Levich equation divided by the electrochemical active surface area determined by the CO stripping method [18]. The electrochemical surface area (ECSA) was defined as the CO stripping charge normalized to $390 \mu \mathrm{C} \mathrm{cm}^{-}$ ${ }^{2} \mathrm{Pt}$ and divided by the Pt mass determined with ICP-MS after leaching and ORR testing. Mass activity (MA) was defined as specific activity multiplied by the ECSA. The rotating disk electrode (RDE) measurements of $\mathrm{O}_{2}$ reduction were carried out in $0.1 \mathrm{M} \mathrm{HClO}_{4}$ solution saturated with $\mathrm{O}_{2}(5 \mathrm{~N} 5$, Air Liquide). The ORR polarization curves were registered at 5 different rotation rates of $816.3,1111,1600$, 2500 , and $4444 \mathrm{rpm}$ at a sweep rate of $100 \mathrm{mV} \mathrm{s}^{-1}$ in the potential range of $0.05 \mathrm{~V}_{\mathrm{RHE}}-1.05 \mathrm{VHE}$. These parameters were taken in accordance with previous publications of Arenz et al. [19]. The KouteckyLevich analysis was carried out at $0.7 \mathrm{~V}_{\mathrm{RHE}}, 0.6 \mathrm{~V}_{\mathrm{RHE}}$ and $0.5 \mathrm{~V}_{\mathrm{RHE}}$.

2.3 Accelerated Stress Testing. The degradation of nanostructured support-free Pt-Cu networks was evaluated with two different accelerated stress test (AST) treatments. The degradation protocols are chosen following the FCCJ recommendations [20]. The first treatment (AST 1) simulates load cycle conditions occurring in a fuel cell in a car and consisted of applying square-wave potential steps between $0.6 \mathrm{~V}_{\mathrm{RHE}}$ and $1.0 \mathrm{~V}_{\mathrm{RHE}}$ with a hold time of $3 \mathrm{~s}$ at each potential. The total treatment lasted 10000 cycles (16 h). The ECSA was measured by H-UPD (hydrogen under potential deposition) of the positive sweep and monitored at the beginning and at the end of the accelerated stress testing. The second accelerated stress test (AST 2) simulates start-up/shutdown conditions. The potential is cycled between $1 \mathrm{~V}_{\mathrm{RHE}}$ and $1.5 \mathrm{~V}_{\mathrm{RHE}}$ with a sweep rate of $500 \mathrm{mV} \mathrm{s}^{-1}$. The total treatment lasted 27000 cycles (15 h). The high potentials simulate start-up conditions when $\mathrm{H}_{2}$ gas at the anode is replaced by air. Under these conditions the cathode can experience high potentials of ca. $1.4 \mathrm{~V}_{\text {RHE }}$ [20]. The ECSA is 
characterized at the beginning and after 27,000 potential cycles. All the measurements were conducted at room temperature in Ar saturated $0.1 \mathrm{M} \mathrm{HClO}_{4}$ without rotation. For more details on these treatments, the reader is referred to the FCCJ protocol [21].

2.4 Microstructure characterization and microanalysis. A Zeiss SUPRA-35 field emission gun scanning electron microscope (SEM) equipped with a ThermoFisher Scientific NSS6 EDS detector was used for imaging and elemental analysis of leached electrodes. SEM images were recorded with the In-lens and Everhart-Thornley (ET) secondary electron (SE) detectors. The In-lens detector primarily detects $\mathrm{SE}_{1}$ type electron for high resolution imaging, for which the resolution is primarily controlled by electron beam diameter (nominally $1 \mathrm{~nm}$ ). The ET detector primarily detects $\mathrm{SE}_{2}$ type electrons that provide tomographic contrast but at a lower resolution than the In-lens detector. Imaging was performed at 5 $\mathrm{keV}$. One area-based EDS analysis was performed per sample at $5 \mathrm{keV}$ to determine Pt:Cu atomic percent ratios. The parameters were chosen to minimise the signal of the carbon substrate. Glassy carbon electrodes were directly positioned on the SEM sample holder without any preparative coating.

2.5 ICP-MS measurements. The Pt loading of the catalysts was determined by using inductively coupled plasma mass spectrometry (ICP-MS) measurements. For this, the catalysts were digested in aqua regia freshly mixed with $30 \% \mathrm{HCl}$ (Suprapur, Merck) and $65 \% \mathrm{HNO}_{3}$ (Suprapur, Merck) in a volumetric ratio of 3:1, respectively. The concentration of platinum in the diluted aqua regia solution was analysed by ICP-MS (NexION 300X, Perkin Elmer) through a Meinhard quartz nebulizer and a cyclonic spray chamber, operating at nebulizer gas flow rates of between 1.00 and $1.02 \mathrm{~L} \mathrm{~min}^{-1}$ (Ar, purity grade 5.0).

2.6 Grazing Incident X-Ray Diffraction (GIXRD). Phase identity and particle size of the Pt-Cu template and the leached catalyst was investigated by the means of a Bruker D8 Advance Diffractometer, with measurements performed at over a 2 Theta range from $30^{\circ}$ to $80^{\circ}$, step width $0.5^{\circ}$ and $5 \mathrm{~s}$ per step.

\section{Results and Discussion}


3.1 As deposited Pt-Cu templates. Five different templates were prepared for obtaining support-free nanostructured catalyst layers. The Cu content as determined by EDS of the templates varied between $95-99.5$ at. \% and the Pt content remained as $0.5-5$ at. \%, see

Table 1 as well as Figures S 1 and S 2. Precise deposition was achieved by tuning the deposition time of $\mathrm{Cu}$. The degree of alloying in the Pt-Cu templates thereby is only minor, the copper mainly plays the role as sacrificial metal to obtain porosity. The XRD patterns are mostly dominated by broad peaks of $\mathrm{Cu}, \mathrm{CuO}$ and $\mathrm{Cu}_{2} \mathrm{O}$ structures which indicate an amorphous structure, see Figure $1 \mathrm{~A}$. No crystalline Pt is detected. In contrast, the diffraction of $\mathrm{Cu}$ in alloyed $\mathrm{Pt}_{3} \mathrm{Cu}_{97}$ are sharp and the $\mathrm{Cu}$ peaks are shifted as Qui et al. showed [22]. Therefore, it can be concluded that a heterogenous agglomeration of Pt and $\mathrm{Cu}$ is sputtered. However, it cannot be excluded from Figure 1 that there might be some very small crystalline Pt areas below the amorphous Cu structures.

The template structure depends of the chosen sputtering parameters. Different sputtering parameters can result in different stress and morphology in the film, but all chosen parameters result in a porous and amorphous film structure, as seen in Figure $2 \mathrm{~A}$. This is in agreement with the "zone model" suggesting porous and amorphous thin film at low RF sputtering power and relatively higher pressure [23].

3.2 Support-free nanostructured Pt-Cu catalyst. In order to form support-free nanostructured Pt-Cu networks from different Pt-Cu templates the $\mathrm{Cu}$ was electrochemically dissolved from the thin film template under potential control in $0.1 \mathrm{M} \mathrm{HClO}_{4}$ electrolyte. The applied leaching procedure is not a typical dealloying procedure as described in literature [10] as dealloying is usually performed by selective dissolution from a homogenous alloy; in contrast, in the presented work a heterogenous thin film was used as template. Although no crystalline Pt was detected in the Pt-Cu templates, the nanostructured Pt-Cu network obtained after $\mathrm{Cu}$ dissolution exhibits crystallinity, see Figure $1 \mathrm{~B}$. Furthermore, the Pt peaks detected after the leaching process are shifted to larger angles as compared to bulk Pt indicating alloy formation during leaching. It is proposed that small Pt "domains" connect 
during the leaching process to form a crystalline, porous network, see Figure 2. The resulting Pt-Cu network exhibits pores in the size range between $5 \mathrm{~nm}$ up to $200 \mathrm{~nm}$. The SEM micrographs indicate that the Pt-Cu networks obtained from $\mathrm{Pt}_{3} \mathrm{Cu}_{97}$ and $\mathrm{Pt}_{5} \mathrm{Cu}_{95}$ templates (see Figure $2 \mathrm{E}$ and $2 \mathrm{~F}$ ) exhibit a lower degree of porosity and a denser structure as compared to the Pt-Cu networks obtained from $\mathrm{Pt}_{0.5} \mathrm{Cu}_{99.5}, \mathrm{Pt}_{1} \mathrm{Cu}_{99}$ and $\mathrm{Pt}_{2} \mathrm{Cu}_{98}$ templates (see Figure $2 \mathrm{~B}, 2 \mathrm{C}$ and $2 \mathrm{D}$ ). The difference between Figure $2 \mathrm{D}$ as $\mathrm{Pt}_{2} \mathrm{Cu}_{98}$ and Figure $2 \mathrm{E}$ as $\mathrm{Pt}_{3} \mathrm{Cu}_{97}$ might actually be the transition point where the formation of the nanoporous network appears. It can be suggested that the pores in the as-prepared films are the initiation points of the leaching as the acid penetrates here first. In Figure $2 \mathrm{~B}$ the large open areas may correspond to the areas where pores were located in the as-prepared films. In these open areas very fine Pt particles can be seen that may or may not be connected to the rest of the catalyst network. Nevertheless it is expected that these Pt particles are still "active“ for the ORR as they are connected to the Ti interlayer on the conductive glassy carbon. The structure of these very small Pt particles cover approximately $10 \%$ of the area. The catalyst can be therefore be divided into coarse and fine regions. The fine part has a fine planar web-like structure that links the coarse regions with a size between 5 and $50 \mathrm{~nm}$. Inside these regions further roughening and porosity is visible. The second dominating structure is the connection between the different clusters which have a size between 2 and $10 \mathrm{~nm}$, which is indicated in Figure $2 \mathrm{G}$ as fine region. Both structures combined result in the nanostructured network, which acts as unsupported catalyst. The same observation of a formation of nanostructured metal is reported for nanoporous Au structures obtained from AgAu alloys. The formation is explained by an equilibrium between surface diffusion of the stable metal $(\mathrm{Au})$ and the dissolution rate of the leached (Ag) metal [10]. Erlebacher et al. [10] state that "[...] pores form because the more noble atoms are chemically driven to aggregate into two-dimensional clusters via a spinodal decomposition process at the solid electrolyte interface." In contrast to dealloying of alloys [10], the here described dissolution process from a heterogenous metal template, to the best of our knowledge has not previously been described in literature. 
The elemental composition after the ORR measurements reveals $\mathrm{Cu}$ concentrations between 13.6 and 46.0 at. \%. These values can be compared with literature values of alloyed PtCu bimetallic microwires synthesized by a melt spinning method. Qui et al. [22] synthesized a melt spun alloy with $\mathrm{Pt}_{3} \mathrm{Cu}_{97}$ - also without visible Pt diffraction peaks before leaching. After leaching this alloy, the atomic ratio of Pt and Cu was 60:40, which compares to an atomic ratio of 65:35 of our leached $\mathrm{Pt}_{3} \mathrm{Cu}_{97}$ template. Most surprising is the observation that the order of the resulting $\mathrm{Cu}$ amount in the nanostructured $\mathrm{Pt}-\mathrm{Cu}$ network is inverse to the initial composition of the templates, see Figure S 2; the highest $\mathrm{Cu}$ amount in the Pt-Cu network after leaching is obtained from the $\mathrm{Pt}_{5} \mathrm{Cu}_{95}$ template. But not only $\mathrm{Cu}$ is lost during leaching, the Pt content decreases as well. The amount of Pt lost during leaching was between $0-20$ $\%$ as measured by ICP without a clear correlation to the initial composition, see Table 1 . The Pt loss seems to be associated to the detachment of larger $\mathrm{Cu}$ areas containing some $\mathrm{Pt}$, but the mechanism was not further investigated.

The ORR activity of the support-free nanostructured Pt-Cu networks was benchmarked in an electrochemical half-cell using the RDE technique. In Figure 3 the Tafel plots for the different samples are shown. All Tafel slopes are similar ranging from 59 to $67 \mathrm{mV} \mathrm{dec}^{-1}$ in the potential window between $0.90 \mathrm{~V}$ and $0.92 \mathrm{~V}$. No clear correlation between the Cu content in the template and Pt-Cu networks, respectively, and the specific ORR activity (at $0.9 \mathrm{~V}_{\mathrm{RHE}}$ ) is observed, see also Table 2 . $\mathrm{Pt}_{5} \mathrm{Cu}_{95}$, the sample with the lowest initial but highest residual Cu content, exhibits a SA of $5.5 \mathrm{~mA} \mathrm{~cm}{ }^{-2} \mathrm{pt}$, whereas for the sample with the highest initial $\mathrm{Cu}$ content $\mathrm{Pt}_{0.5} \mathrm{Cu}_{99.5}$ a SA of $3.1 \mathrm{~mA} \mathrm{~cm}{ }^{-2}$ is is observed, see also Figure S 3. These specific ORR activities exceed the ones of bulk Pt (2.1 mA cm$\left.{ }^{-2}{ }_{\mathrm{Pt}}[5]\right)$ and Pt-Cu nanoparticles (0.8 $\mathrm{mA} \mathrm{cm}^{-2} \mathrm{pt}$ with $5 \mathrm{mV} \mathrm{s}^{-1}$ [24] or $1.78 \mathrm{~mA} \mathrm{~cm} \mathrm{pt}^{-2}$ with $50 \mathrm{mV} \mathrm{s}^{-1}$ [25]), respectively. It should be mentioned that part of these values are (as indicated) at different scan rates, however, the specific activity measured at $5 \mathrm{mV} \mathrm{s}^{-1}$ can be multiplied by 2 in order to get comparable results to measurements taken at $50 \mathrm{mV} \mathrm{s}^{-1}$ [26]. The highest specific ORR activity of $5.8 \mathrm{~mA} \mathrm{~cm}^{-2} \mathrm{Pt}$ is found for sample $\mathrm{Pt}_{3} \mathrm{Cu}_{97}$ with 35 at. \% Cu remaining, see also Figure 4 . The number of electrons transferred during the ORR was calculated using Koutecky-Levich plots at the potentials $0.7 \mathrm{~V}_{\mathrm{RHE}}, 0.6 \mathrm{~V}_{\mathrm{RHE}}$ and 0.5 
$\mathrm{V}_{\mathrm{RHE}}$, see Figure 5 and Figure $\mathrm{S} 4$. All values are close to 4 , for $\mathrm{Pt}_{0.5} \mathrm{Cu}_{99.5}$ the calculated number is 3.89 , for $\mathrm{Pt}_{1} \mathrm{Cu}_{99} 3.85$ electrons, for $\mathrm{Pt}_{2} \mathrm{Cu}_{98}$ 3.86, for $\mathrm{Pt}_{3} \mathrm{Cu}_{97} 3.94$ and for $\mathrm{Pt}_{5} \mathrm{Cu}_{95}$ 4.21. The corresponding diffusion coefficient, viscosity and bulk concentration of oxygen can be found in [13]. The value for $\mathrm{Pt}_{5} \mathrm{Cu}_{95}$ is above the theoretical number of 4 electrons indicating that there is an ongoing structural change coupled with copper dissolution.

Analysing the surface area of the Pt-Cu networks (after leaching) by the CO stripping technique, ECSA values between $19 \mathrm{~m}^{2} \mathrm{gPt}^{-1}$ and $47 \mathrm{~m}^{2} \mathrm{~g}_{\mathrm{Pt}}{ }^{-1}$ were determined. In contrast to the $\mathrm{SA}$, it is observed that the ECSA is higher for the samples with high initial $\mathrm{Cu}$ content. The highest ECSA of $47 \mathrm{~m}^{2} \mathrm{gpt}^{-1}$ is observed for sample $\mathrm{Pt}_{2} \mathrm{Cu}_{98}$; the lowest ECSA of $19 \mathrm{~m}^{2} \mathrm{gPt}^{-1}$ for sample $\mathrm{Pt}_{5} \mathrm{Cu}_{95}$, see also Figure $\mathrm{S}$ 5. The maximum ECSA of $47 \mathrm{~m}^{2} \mathrm{gPt}^{-1}$ achieved here, is comparable to the ECSA reported for carbon supported PtCu nanoparticles [24] and for nanostructured $\mathrm{Pt}_{3} \mathrm{Cu}_{97}$ synthesized by the melt spinning method [22]. The different ECSA values are correlated with the structures of the Pt-Cu networks observed by SEM, see Figure 2. As mentioned above, the networks obtained from samples $\mathrm{Pt}_{0.5} \mathrm{Cu}_{95.5}, \mathrm{Pt}_{1} \mathrm{Cu}_{99}$ and $\mathrm{Pt}_{2} \mathrm{Cu}_{98}$ have a more porous structure, whereas the networks obtained from $\mathrm{Pt}_{3} \mathrm{Cu}_{97}$ and $\mathrm{Pt}_{5} \mathrm{Cu}_{95}$ have a denser, less porous structure. This indicates that an extremely high copper content is required for formation of a porous network Pt-Cu with high electrochemically active surface area. The high surface area result in mass activities of the support-free nanostructured Pt-Cu networks between $1.1 \mathrm{~A} \mathrm{mg}^{-1}$ and $1.9 \mathrm{~A}$ $\mathrm{mg}_{\mathrm{Pt}^{-1}}$, see Table 1 and Figure 4. The highest mass activity of $1.9 \mathrm{~A} \mathrm{mg}_{\mathrm{Pt}}{ }^{-1}$ is achieved from the $\mathrm{Pt}_{3} \mathrm{Cu}_{97}$ template, the Pt-Cu network with the highest SA and a moderately high ECSA of $32 \mathrm{~m}^{2} \mathrm{gPt}^{-1}$. The samples with higher dispersion (ECSA) could not achieve the same mass activity, because the SA was too low. In comparison with the reported activities of $\mathrm{PtCu} / \mathrm{C}$ catalysts of $0.4 \mathrm{~A} \mathrm{mg} \mathrm{pt}^{-1}$ prepared by Strasser et al. [24], the nanostructured $\mathrm{Pt}_{3} \mathrm{Cu}_{97}$ network is nearly 5 times as active. This difference in $\mathrm{MA}$ is not due to different surface areas, which are (as mentioned above) comparable in both cases, i.e. the improved MA of the support-free nanostructured Pt-Cu network originates from the higher specific activity. Another comparison can be done with the PtCu/C catalyst prepared by Hodnik et al. [25]. The authors report a mass activity of $0.45 \mathrm{~A} \mathrm{mg}_{\mathrm{Pt}}^{-1}$ and a moderately high SA (1.78 $\left.\mathrm{mA} \mathrm{cm}_{\mathrm{Pt}}{ }^{-2}\right)$ and ECSA (25 
$\left.\mathrm{m}^{2} \mathrm{gpt}^{-1}\right)$. From these works it is apparent that in general high surface area is achieved at the expense of a lower SA. By comparison the presented support-free Pt-Cu networks combine a relatively high ECSA which is comparable to supported nanoparticles with a very high SA, which is typical for bulk catalysts resulting in an optimized MA. The main reason for the high SA is thereby attributed to subsurface $\mathrm{Cu}$ in the Pt-Cu network known to lead to compressive strain in the Pt surface [27]. The strain weakens the binding between Pt and $\mathrm{O}$ intermediated leading to optimized ORR rates as compared to bulk Pt. A more detailed discussion of the "strain effect" can be found in the work of Strasser et al. [27]. From the prepared catalysts, it appears that for an "optimal strain effect" a remaining $\mathrm{Cu}$ content above 20 at \% $\mathrm{Cu}$ is required; i.e. comparing for the two Pt-Cu networks with high residual $\mathrm{Cu}$ content obtained from the $\mathrm{Pt}_{3} \mathrm{Cu}_{97}$ and $\mathrm{Pt}_{5} \mathrm{Cu}_{95}$ templates, it is seen that the $\mathrm{SA}$ stays relatively constant although the remaining $\mathrm{Cu}$ content in the two networks is quite different. However, such comparisons must be taken with care as in addition to the strain effect, the SA improvement is also related to the nanostructure of the catalyst. It is apparent that the nanoparticle-based catalysts discussed in literature, all have a lower SA $[24,28]$. It is known that edges and defects can have a major influence on the SA of a catalyst and are often related to the often-discussed particle size effect of the ORR[6]. It can therefore be speculated that the nanostructure formation during the leaching process influences the SA in addition to the $\mathrm{Cu}$ content and the accompanied strain formation. Furthermore, the leaching and accompanied metal loss leads to difference in porosity which influences the mass transport. It is therefore an interesting observation that the template with the highest initial $\mathrm{Cu}$ amount has the lowest residual Cu content in the Pt-Cu network, see Table 1.

3.3 Durability. In addition to the activity, the stability of a catalyst is essential. Accelerated stress testing of the support-free Pt-Cu networks indicate that even though the catalysts are support free, they exhibit degradation. We distinguish in the accelerated stress tests between simulated load cycles (AST 1) and simulated start-up/shutdown conditions (AST 2), see experimental sections. Both treatments lead to the loss of Pt, however, the Pt loss upon AST 1 is higher than for AST 2. For example: the Pt loading (as determined by ICP-MS) of the dealloyed $\mathrm{Pt}_{1} \mathrm{Cu}_{99}$ network decreases from $16.4 \mu \mathrm{g}_{\mathrm{Pt}} \mathrm{cm}^{-2}$ to 
$13.0 \mu \mathrm{g}_{\mathrm{Pt}} \mathrm{cm}^{-2}$ (21\% loss) after AST 1 and to $14.2 \mu \mathrm{g}_{\mathrm{Pt}} \mathrm{cm}^{-2}$ (13\% loss) after AST 2, see Table 3. The loss of $\mathrm{Pt}$ is accompanied with a loss in ECSA (calculated with respect to the initial Pt loading) of $42 \%$ (AST 1) and $8 \%$ (AST 2), respectively. The respective values for the Pt-Cu network obtained from the $\mathrm{Pt}_{3} \mathrm{Cu}_{97}$ template can be found in Table 3. The observed loss of Pt during cycling in the Pt oxide region is a known limitation of Pt-based catalysts for the oxygen reduction reaction in fuel cells and in accordance with studies by Mayrhofer et al. [29]. It is accompanied by a decrease in specific ORR activity, which decreases to the value of bulk Pt, see Figure 6 and Figure 7. This means that as compared to pristine $\mathrm{Pt} / \mathrm{C}$ the SA is still $2-4$ times higher. Interestingly, Pt loss and ECSA loss do not correlate. For AST 1, the ECSA loss is higher than the relative loss of Pt, whereas for AST 2 it is smaller. As a consequence, during AST 2 the ECSA calculated with respect to the remaining Pt content of the catalyst slightly increases, see Figure 6 and 7. This indicates that Pt loss at high potential exposure is not only relatively small, but is even to a small degree counterbalanced by surface roughening. This is in contrast to $\mathrm{Pt} / \mathrm{C}$ catalysts where significant carbon corrosion and concomitant particle loss occurs under such AST treatments[30]. Comparing the degradation data to conventional Pt/C catalysts [20] (in this work all values are normalized to the data of the initial Pt loading) a similar decrease in ECSA (30 - $45 \%$ ) during AST 1 (9000 cycles) is seen, whereas the loss of ECSA during AST 2 can be significantly higher (between $15 \%-50 \%$ with 27000 cycles) depending on nominal Pt loading and the type of carbon support [31]. Comparing the observed degradation to PtCu/C Strasser et al. report no degradation data, but Hodnik et al. reported the MA loss for an AST protocol consisting of 7000 potential cycles between $0.6 \mathrm{~V}_{\text {RHE }}$ to $1.2 \mathrm{~V}_{\mathrm{RHE}}$ with a scan rate of $1 \mathrm{~V} \mathrm{~s}^{-1}$. The degradation protocol used by Hodnik et al. is not standard, but it might be compared to AST 1. It has a higher upper potential limit (1.2 $\mathrm{V}_{\mathrm{RHE}}$ compared to $1.0 \mathrm{~V}_{\mathrm{RHE}}$ ), but fewer cycles (7000 cycles at $1 \mathrm{~V} \mathrm{~s}^{-1}$ compared to 10000 steps with $3 \mathrm{~s}$ hold time). Hodnik et al. report a decrease in MA of PtCu/C from $0.45 \mathrm{~A} \mathrm{mg}_{\mathrm{Pt}^{-1}}$ to $0.3 \mathrm{~A} \mathrm{mg}^{-1}$ (decrease to $67 \%$ of initial value). By comparison the $\mathrm{Pt}-\mathrm{Cu}$ network obtained from the $\mathrm{Pt}_{1} \mathrm{Cu}_{99}$ template exhibited a decrease in $\mathrm{MA}$ from 1.21 $\mathrm{A} \mathrm{mg}_{\mathrm{Pt}^{-1}}$ to $0.57 \mathrm{~A} \mathrm{mg}^{-1}$ (decrease to $47 \%$ of initial value) and the Pt-Cu network with the highest initial MA (obtained from the $\mathrm{Pt}_{3} \mathrm{Cu}_{97}$ template) even exhibited a decrease in MA from $1.85 \mathrm{~A} \mathrm{mg}_{\mathrm{Pt}^{-1}}$ to 
$0.51 \mathrm{~A} \mathrm{mg} \mathrm{t}^{-1}$ (decrease to $28 \%$ of initial value). As the ECSA significantly decreases during AST 1 but only slightly during AST 2, the difference in the origin of the degradation is apparent. During AST 1 the loss in MA is a combination of dealloying and surface area loss, whereas during AST 2, for origin of the loss in MA is only dealloying, see also Figure 6 and 7, where we normalize the activities and ECSA to the remaining Pt content after the stress test.

From the AST treatments, it is apparent that the high MA of the Pt-Cu networks resulting from high SA combined with high ECSA cannot be retained during stress testing. This has already been shown for alloyed catalysts by Chen et al. in fuel cell tests reporting a decrease in SA by $40 \%$ [32]. However, for start-stop conditions (simulated in AST 2), which is known to lead to massive carbon support corrosion in supported catalysts, the support-free Pt-Cu networks have an advantage. In the SEM micrographs of the networks obtained after the accelerated stress testing it can be seen that the catalyst structure is relatively stable during AST 2 but agglomerated after AST 1, see Figure 8 . Therefore, such systems might be feasible options for applications with a high number of start-ups and shut-downs.

\section{Conclusion}

Different $\mathrm{Pt}_{\mathrm{x}} \mathrm{Cu}_{\mathrm{y}}$ templates were synthesized by an alternating sputtering of $\mathrm{Pt}$ and $\mathrm{Cu}$ in a plasmabased method. The formation of the catalyst nanostructure is triggered by electrochemical leaching of the $\mathrm{Cu}$. To the best of our knowledge this is the first time where this could be achieved with heterogeneous, amorphous template materials and a Cu content up to 99.5 at.\%. Electron microscopy reveals a support-free, porous nanostructured Pt-Cu network with a large surface area. This correlates to the high electrochemical surface area measured by $\mathrm{CO}$ oxidation in the electrochemical cell. Surprisingly the remaining $\mathrm{Cu}$ content in the networks is higher with templates having lower initial copper content. The support-free Pt-Cu networks exhibited specific activities for the oxygen reduction reaction between $2.9 \mathrm{~mA} \mathrm{~cm}{ }^{-2} \mathrm{pt}$ and $5.8 \mathrm{~mA} \mathrm{~cm}^{-2} \mathrm{Pt}$. The specific activity not only depends on the remaining $\mathrm{Cu}$ in the catalyst after leaching but also on the surface structure ( e.g. defects and edges) of the catalyst. At the same time, it was possible to achieve high electrochemical active surface areas 
of up to $47 \mathrm{~m}^{2} \mathrm{~g}^{-1} \mathrm{Pt}$ leading to superior mass activities as compared to conventional Pt-Cu nanoparticles supported on carbon. Nevertheless, the network catalysts exhibit limited stability. In accelerated stress tests a decrease in specific activities to the value of Pt bulk activity is observed indicating complete dealloying. Upon degradation cycles from $0.6 \mathrm{~V}_{\mathrm{RHE}}$ to $1 \mathrm{~V}_{\mathrm{RHE}}$ the degradation of the network catalysts is comparable to $\mathrm{Pt} / \mathrm{C}$ and $\mathrm{PtCu} / \mathrm{C}$ catalysts indicating that the degradation upon such treatment is strongly influenced by a support. Accelerated stress testing from $1 \mathrm{~V}_{\mathrm{RHE}}$ to $1.5 \mathrm{~V}_{\mathrm{RHE}}$, however, indicates a beneficial effect of a support-free catalyst with almost no loss in electrochemical surface area. This is in contrast to carbon supported catalysts, where the degradation upon cycling from $1 \mathrm{~V}_{\mathrm{RHE}}$ to $1.5 \mathrm{~V}_{\mathrm{RHE}}$ leads to severe carbon corrosion.

\section{Acknowledgement}

This work was supported by the Danish Innovation Fund (4 M center) and the Danish DFF through grant \# 4184-00332.

Table 1: Composition Pt-Cu samples measured by EDS* and ICP-MS

EDS Pt

\begin{tabular}{|c|c|c|c|c|c|}
\hline & at\% & at\% & at\% & at\% & Pt lost** \\
\hline $\begin{array}{l}\text { Pt-Cu } \\
\text { samples }\end{array}$ & as prepared & after ORR & as prepared & after ORR & \\
\hline $\mathrm{Pt}_{5} \mathrm{Cu}_{95}$ & $4.7 \pm 0.2$ & $53.9 \pm 2.2$ & $95.2 \pm 0.8$ & $46.0 \pm 2.5$ & $9.1 \%$ \\
\hline $\mathrm{Pt}_{3} \mathrm{Cu} \mathrm{u}_{97}$ & $3.1 \pm 0.2$ & $65.4 \pm 2.9$ & $96.8 \pm 1.0$ & $35.2 \pm 2.3$ & $0 \%$ \\
\hline $\mathrm{Pt}_{2} \mathrm{Cu}_{98}$ & $2.0 \pm 0.2$ & $81.5 \pm 3.2$ & $97.9 \pm 0.9$ & $18.4 \pm 1.7$ & $22.1 \%$ \\
\hline $\mathrm{Pt}_{1} \mathrm{Cu} \mathrm{ug}_{99}$ & $1.2 \pm 0.2$ & $85.8 \pm 3.0$ & $98.7 \pm 0.8$ & $14.1 \pm 1.5$ & $3.4 \%$ \\
\hline
\end{tabular}




\begin{tabular}{|c|c|c|c|c|}
\hline $\mathrm{Cu}_{99.5}$ & $0.5 \pm 0.2$ & $86.3 \pm 4.5$ & $99.4 \pm 1.1$ & $13.6 \pm 2.3$ \\
\hline
\end{tabular}

* estimation of the uncertainty in the $\mathrm{Pt}-\mathrm{Cu}$ at\% ratios is non-trivial due to the porous nature of the electrodes and expected to be not less than $1 \%$

**measured by ICP-MS before and after electrochemical testing 

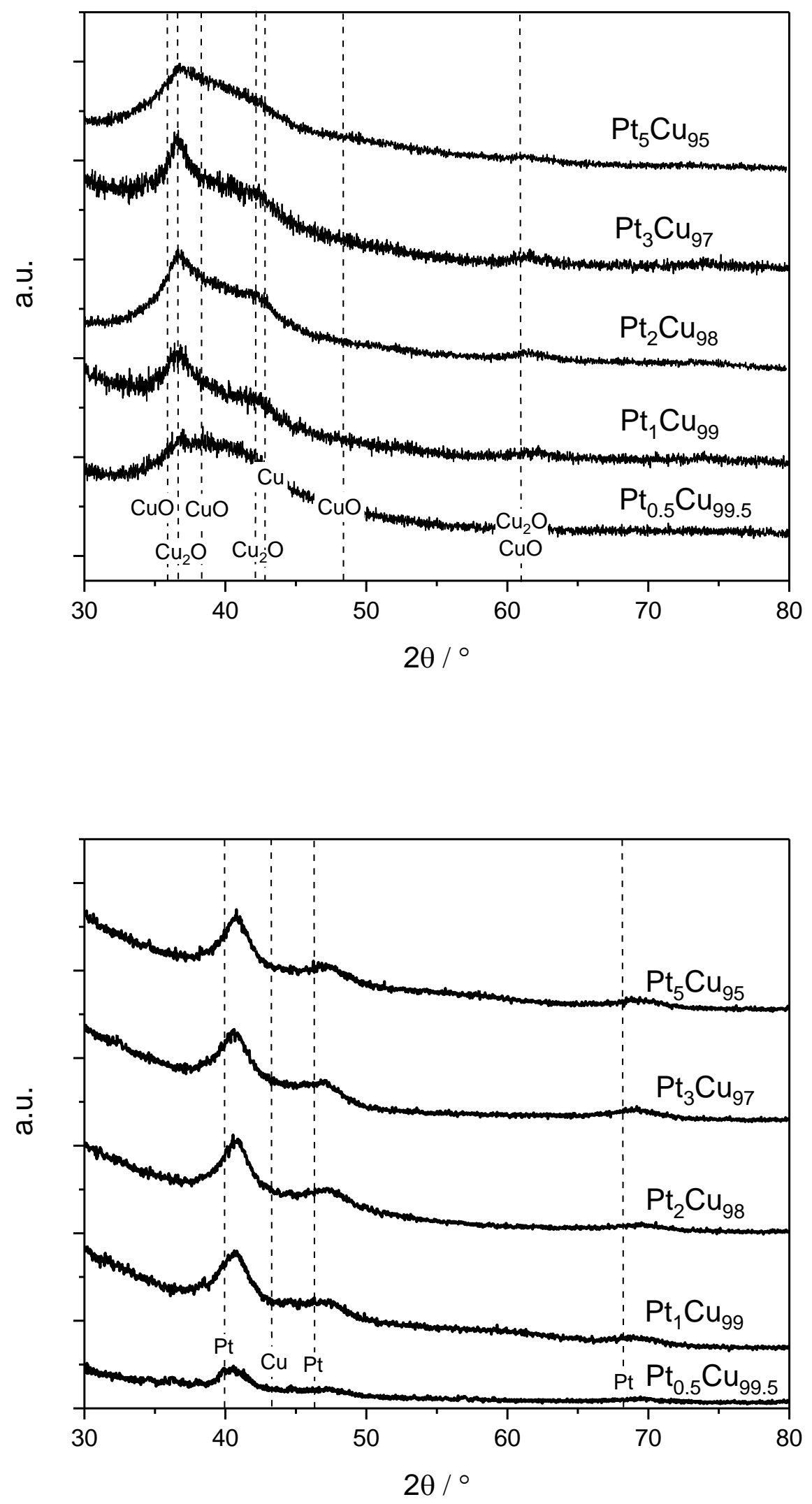
Figure 1: Grazing incident X-Ray diffraction patterns with a step width of $0.5^{\circ}$ and $5 \mathrm{~s}$ per step of (A) $\mathrm{Pt}_{\mathrm{x}} \mathrm{Cu}_{\mathrm{y}}$ templates as deposited and (B) leached, nanostructured $\mathrm{Pt}$-Cu networks (labelled by the $\mathrm{Pt}_{\mathrm{x}} \mathrm{Cu}_{\mathrm{y}}$ template composition). In the diffraction patterns the following dashed lines are included: PDF 00-0031015 Cu, PDF 00-005-0667 Cu2 +1 O Cuprite, PDF 00-003-0884 CuO Tenorite, PDF 00-001-1194 Pt.

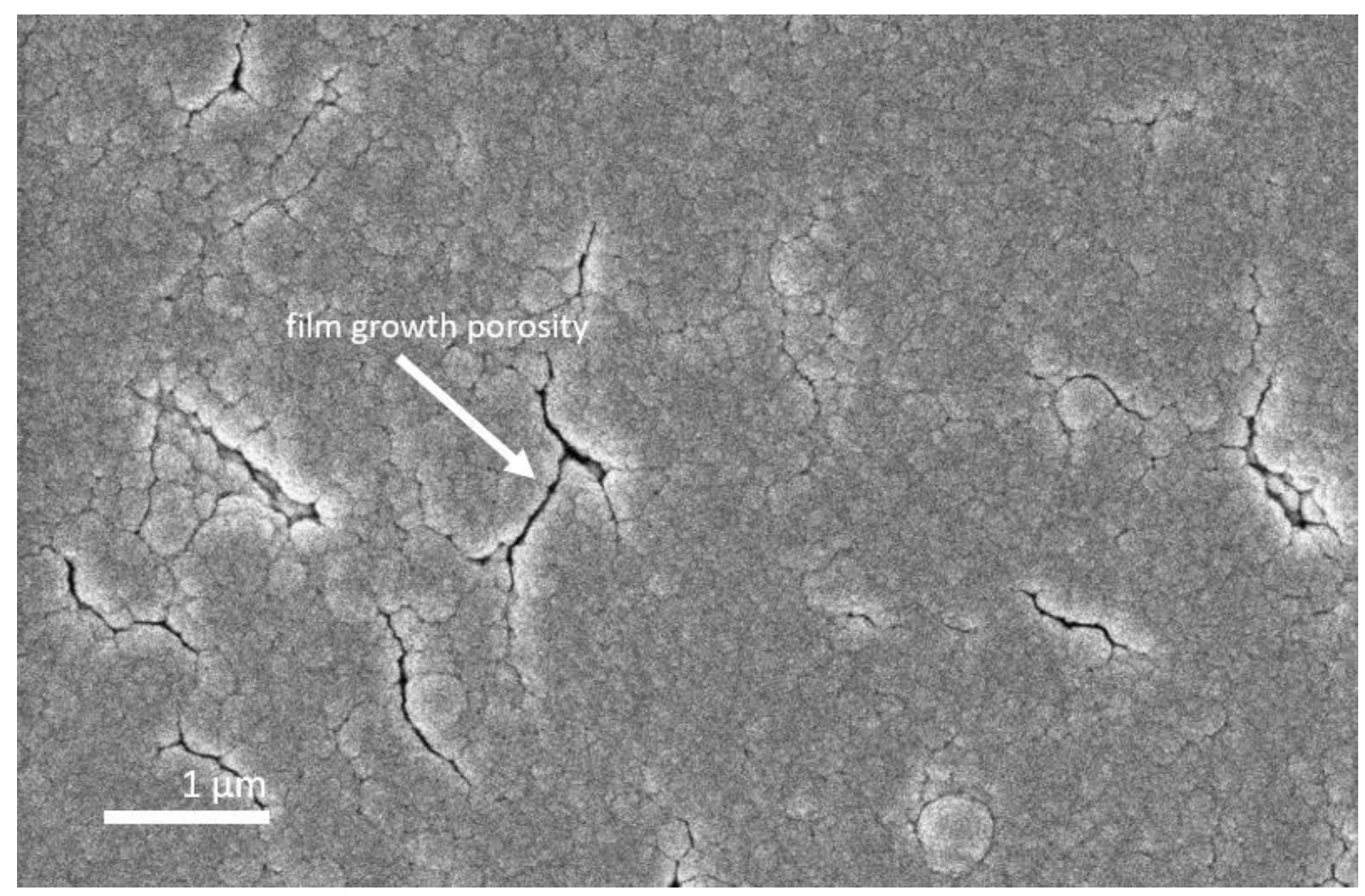

(A) 


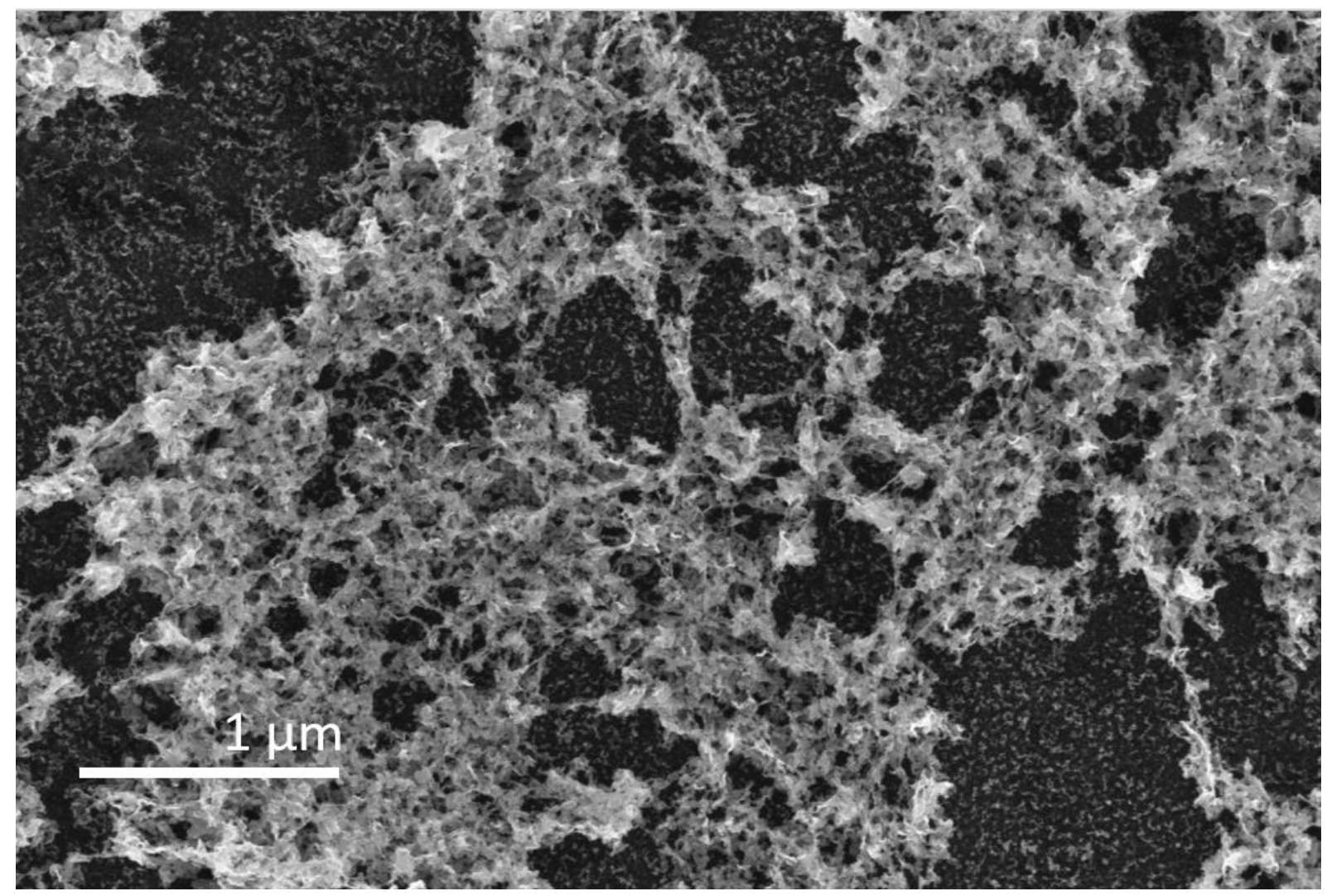

(B)

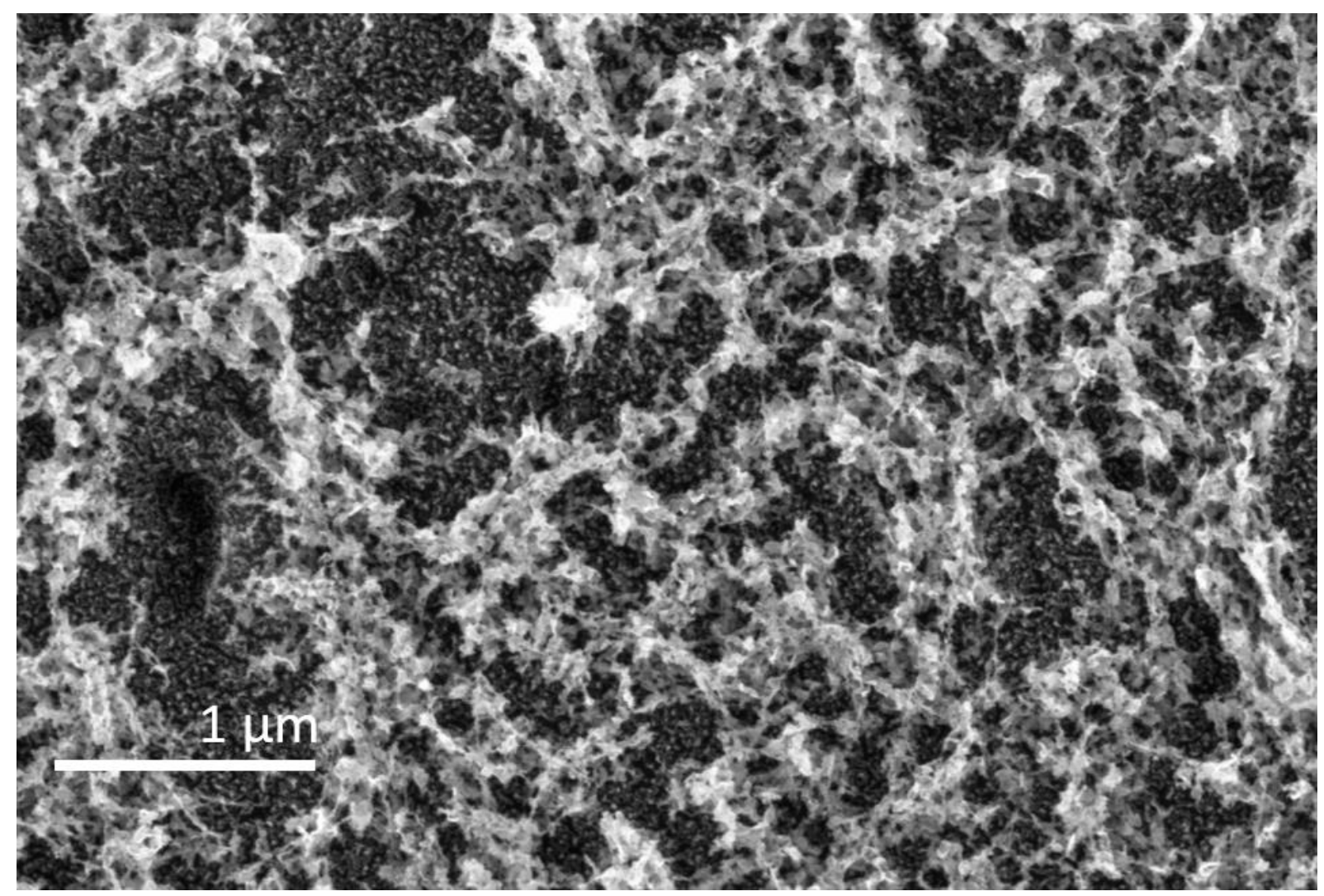


(C)

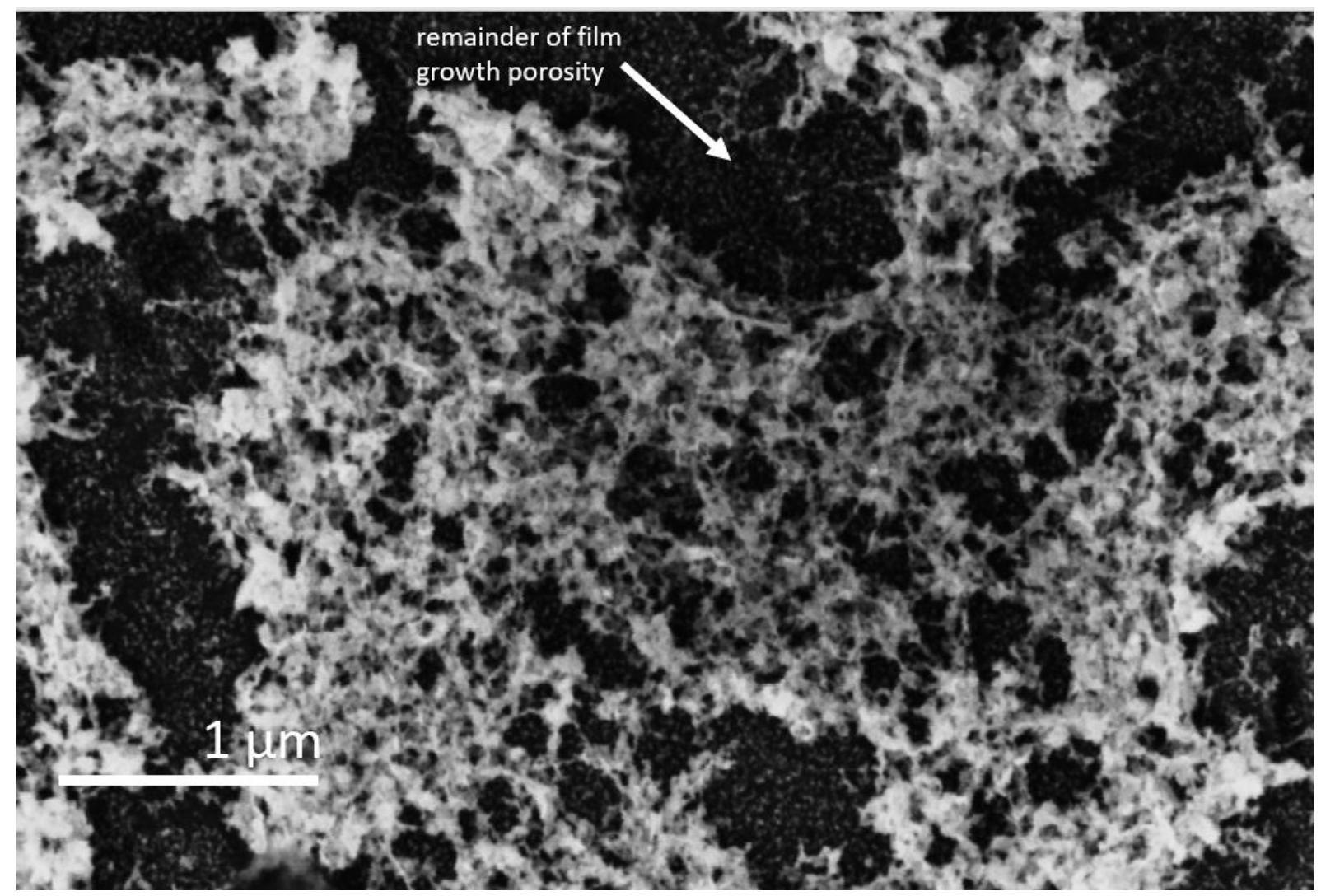

(D)

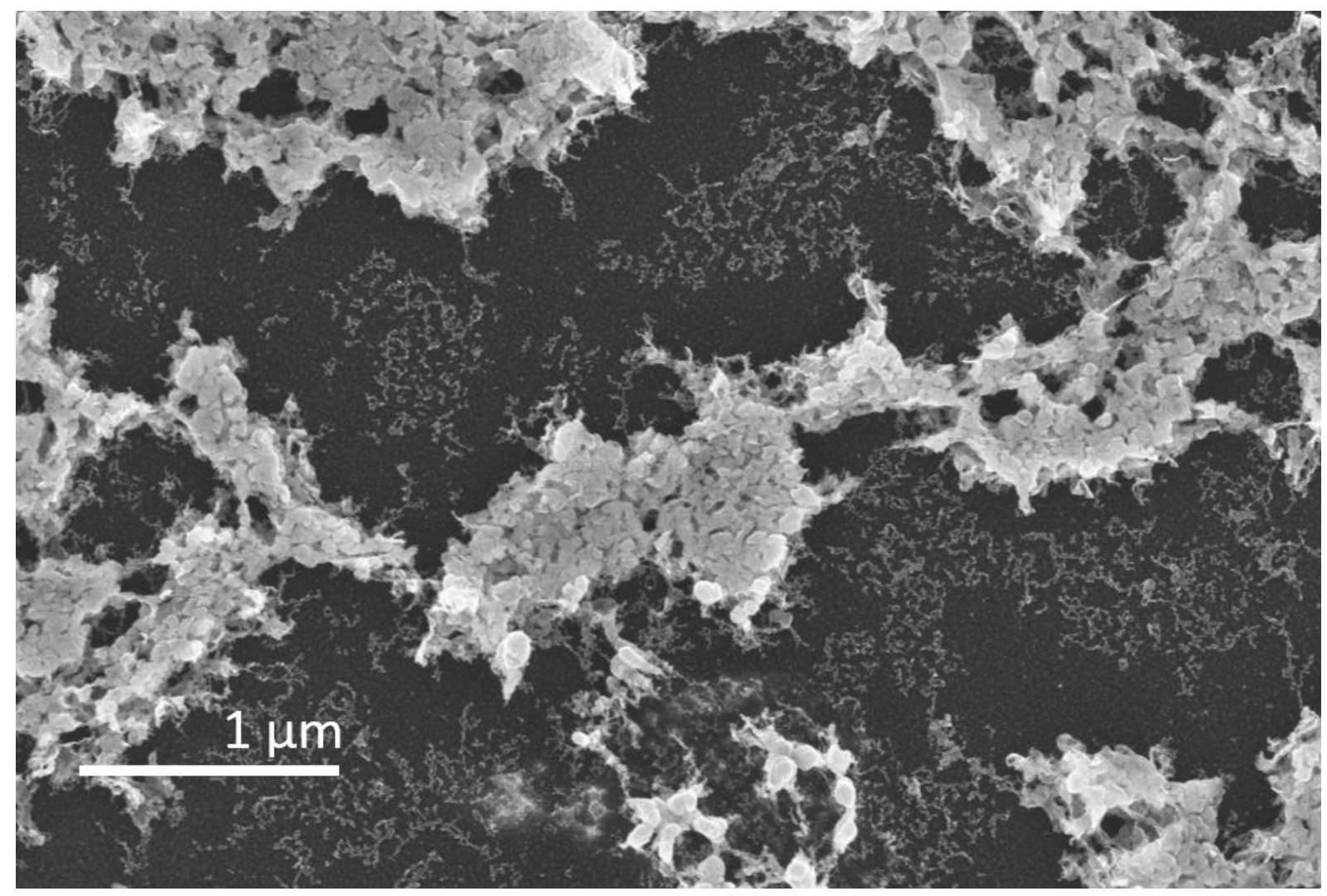

(E) 


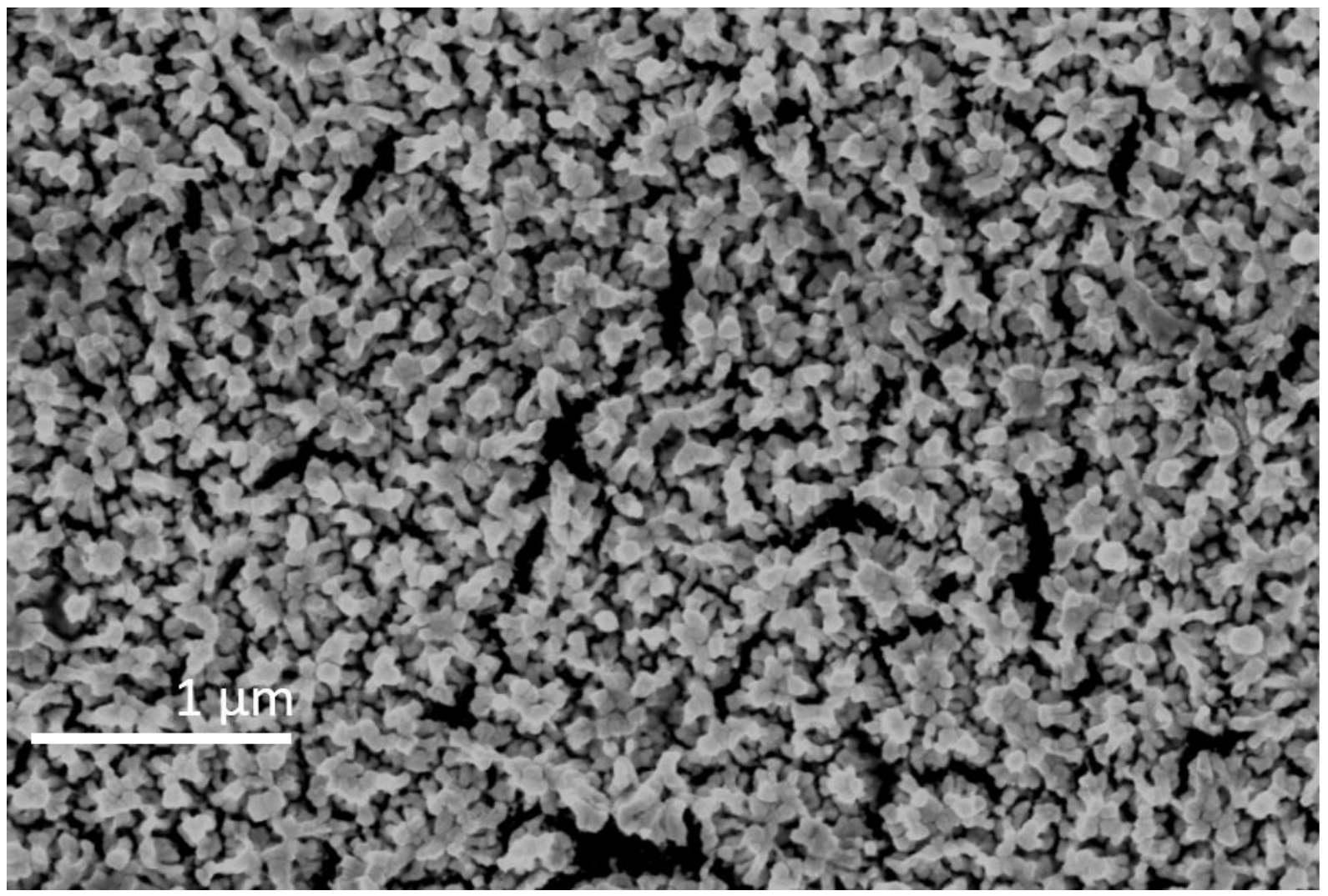

(F)

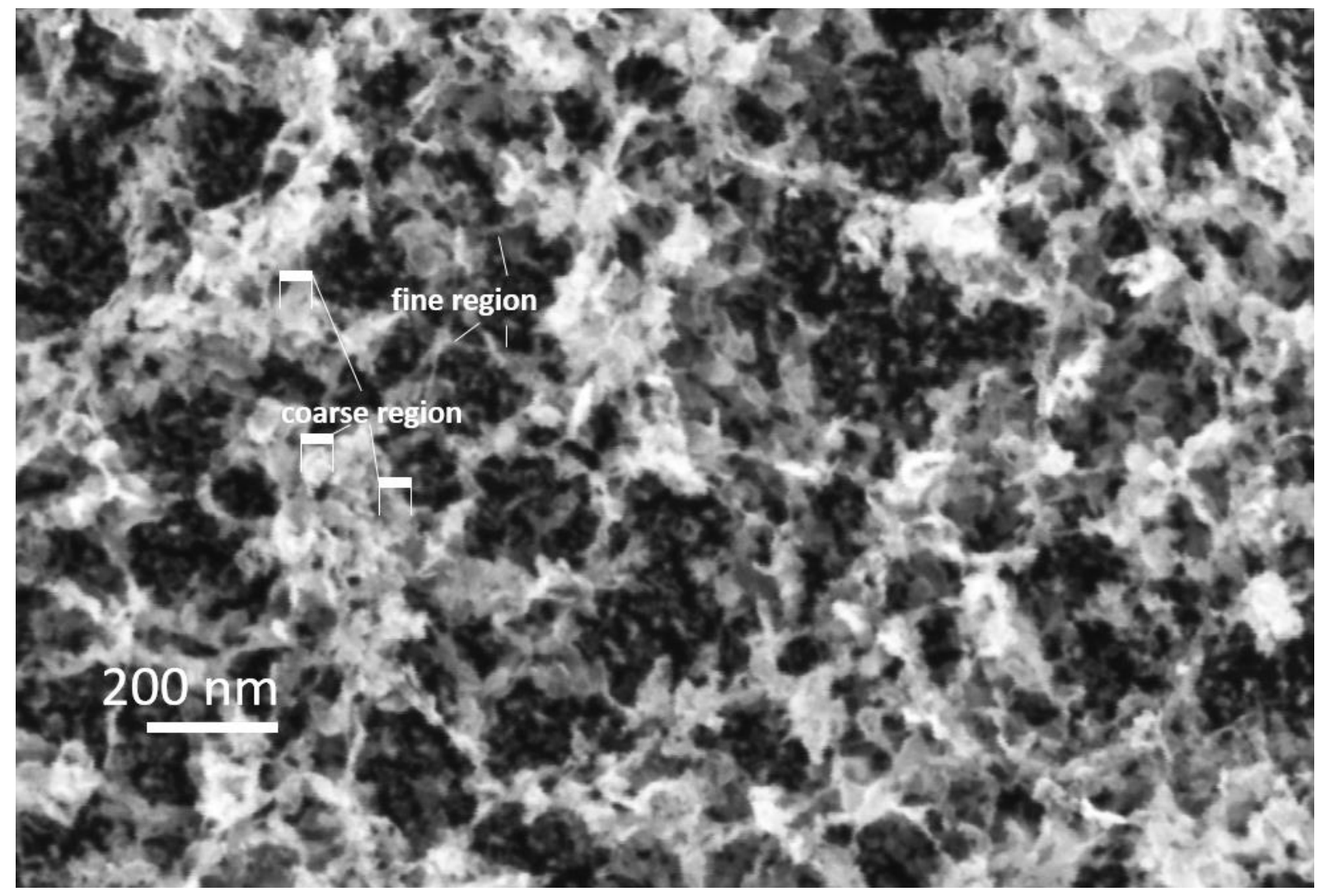

(G) 
Figure 2: In-Lens secondary electron SEM Micrograph measured at $5 \mathrm{kV}$ of $(\mathrm{A})$ as deposited $\mathrm{Pt}_{1} \mathrm{Cu}_{99}$, (B) leached $\mathrm{Pt}_{0.5} \mathrm{Cu}_{99.5, \mathrm{c}}(\mathrm{C})$ leached $\mathrm{Pt}_{1} \mathrm{Cu}_{99}$, (D) leached $\mathrm{Pt}_{2} \mathrm{Cu}_{98}$, $(\mathrm{E})$ leached $\mathrm{Pt}_{3} \mathrm{Cu}_{97}$, $(\mathrm{F})$ leached $\mathrm{Pt}_{5} \mathrm{Cu}_{95}$, and $(\mathrm{G})$ a higher resolution SEM Micrograph of leached $\mathrm{Pt}_{1} \mathrm{Cu}_{99}$

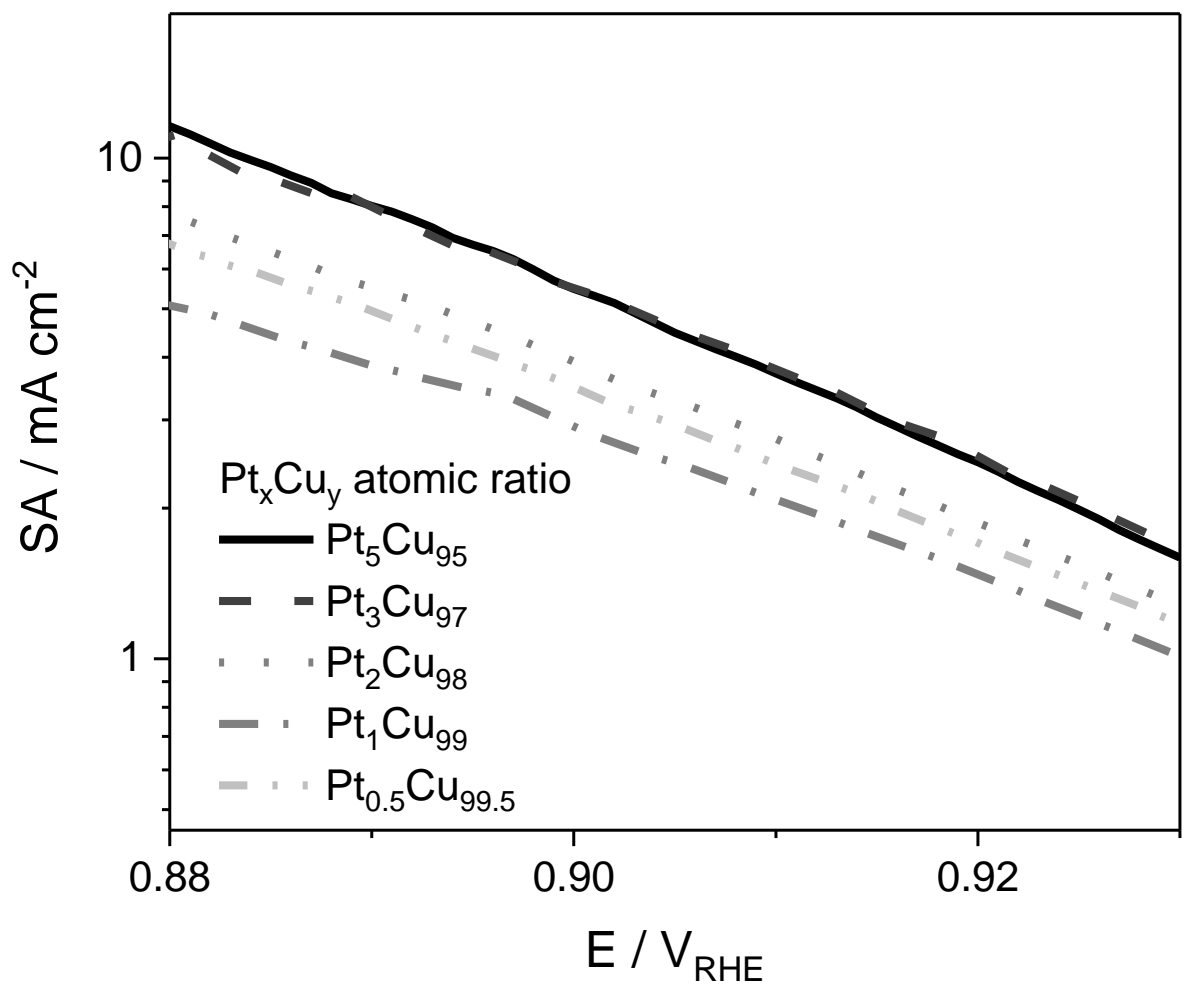

Figure 3: Tafel plots of specific ORR activity for different synthesized catalysts in $0.1 \mathrm{M} \mathrm{HClO}_{4}$ at $50 \mathrm{mV}$ $\mathrm{s}^{-1} \mathrm{cycled}$ between $0.05 \mathrm{~V}$ and $1.1 \mathrm{~V}$ vs. RHE corrected for capacitive background and internal resistance; The specific ORR activities were obtained from RDE measurements in $0.1 \mathrm{M} \mathrm{HClO}_{4}$ electrolyte using a rotation rate of $1600 \mathrm{rpm}$ and a scan rate $50 \mathrm{mV} \mathrm{s}^{-1}$ at room temperature.

Table 2: Summary of the ORR activities of different prepared nanostructured Pt-Cu samples

\begin{tabular}{cllr} 
Pt-Cu sample & SA@0.9V & MAE $@ 0.9 V_{\mathrm{RHE}}$ & ECSA* \\
& {$\left[\mathrm{mA} \mathrm{cm}{ }^{-2}{ }_{\mathrm{Pt}}\right]$} & {$\left[\mathrm{A} \mathrm{mg}^{-1} \mathrm{Pt}\right]$} & 19 \\
\hline $\mathrm{Pt}_{5} \mathrm{Cu}_{95}$ & $5.51 \pm 0.05$ & 1.05 & 32 \\
$\mathrm{Pt}_{3} \mathrm{Cu}_{97}$ & $5.78 \pm 0.29$ & 1.85 & $\left.\mathrm{~m}^{-1}{ }_{\mathrm{Pt}}\right]$ \\
\hline
\end{tabular}




\begin{tabular}{c|lcc} 
Pt $_{2} \mathrm{Cu}_{98}$ & $3.34 \pm 0.61$ & 1.58 & 47 \\
Pt $_{1} \mathrm{Cu}_{99}$ & $2.91 \pm 0.47$ & 1.21 & 41 \\
Pt $_{0.5} \mathrm{Cu}_{99.5}$ & $3.13 \pm 0.36$ & 1.41 & 45 \\
PT-CU REFERENCE 1** & 0.83 & 0.41 & 47 \\
\hline PT-CU REFERENCE 2*** & 1.78 & 0.45 & 25 \\
Pt/C REFERENCE**** & 0.51 & 0.55 & 108 \\
Pt REFERENCE**** & 2.1 & - & - \\
*measured by CO stripping and ICP-MS Pt quantification
\end{tabular}

- $\quad * *$ Strasser et al. [24] with $5 \mathrm{mV} \mathrm{s}^{-1}$

- $\quad * * *$ Hodnik et al. [25] PtCu/C (Q) CV with $50 \mathrm{mV} \mathrm{s}^{-1}$

- $\quad * * * *$ Nesselberger et al.[5] measured with the same conditions in the same lab

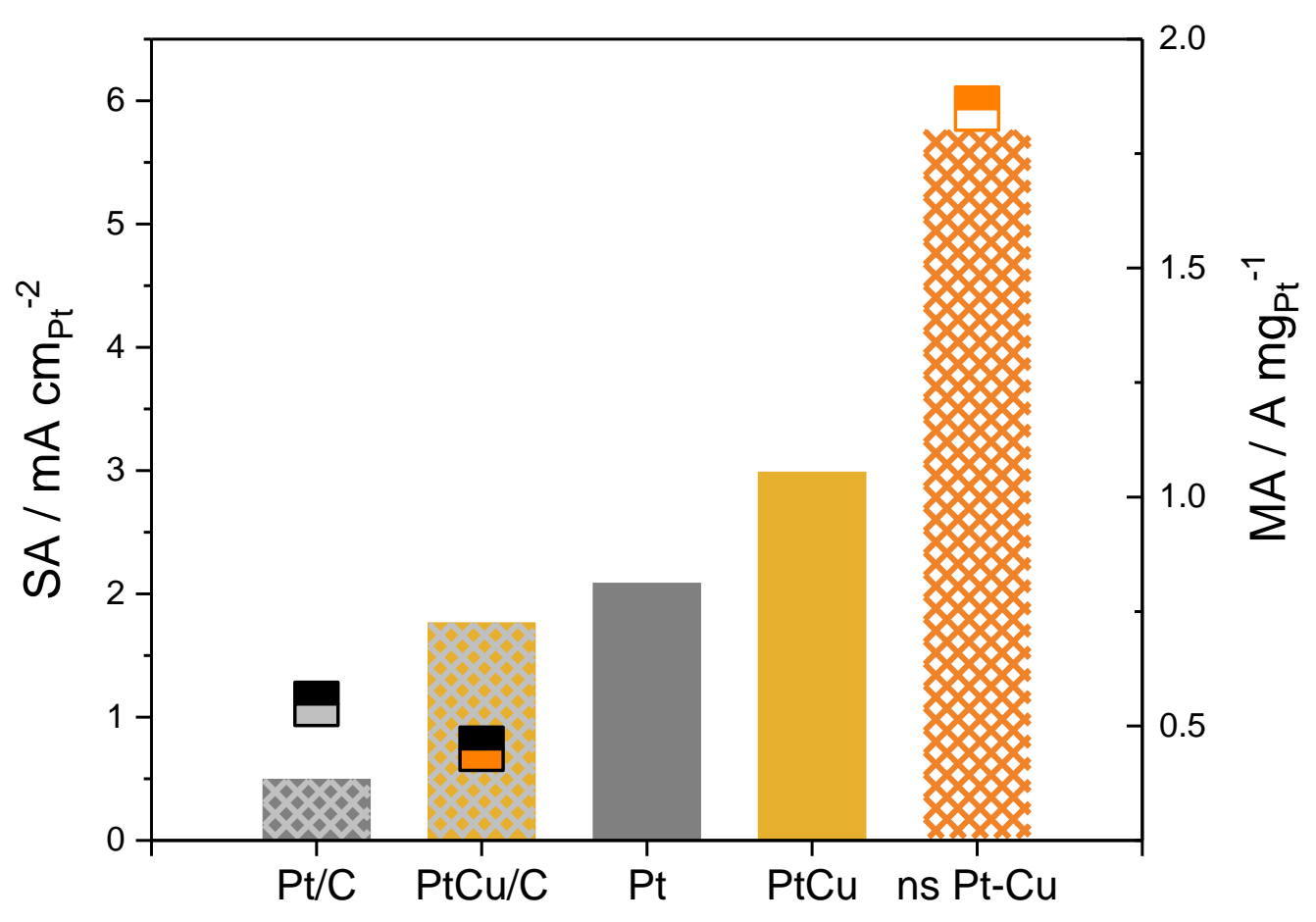


Figure 4: Comparison of the specific ORR activity (left axis, bars) and the mass activity (right axis, box scatter) of nanostructured Pt-Cu $\left(\mathrm{Pt}_{3} \mathrm{Cu}_{97}\right)$ determined by $\mathrm{RDE}$ in $0.1 \mathrm{M} \mathrm{HClO}_{4}$ electrolyte using a rotation rate of $1600 \mathrm{rpm}$ and a scan rate $50 \mathrm{mV} \mathrm{s}^{-1}$ at room temperature. References taken from Pt/C and Pt with $50 \mathrm{mV} \mathrm{s}^{-1}$ from Nesselberger et al.[5], PtCu/C with $50 \mathrm{mV} \mathrm{s}^{-1}$ from Hodnik et al.[25] and PtCu with $20 \mathrm{mV} \mathrm{s}^{-1}$ from Yang et al.[33]

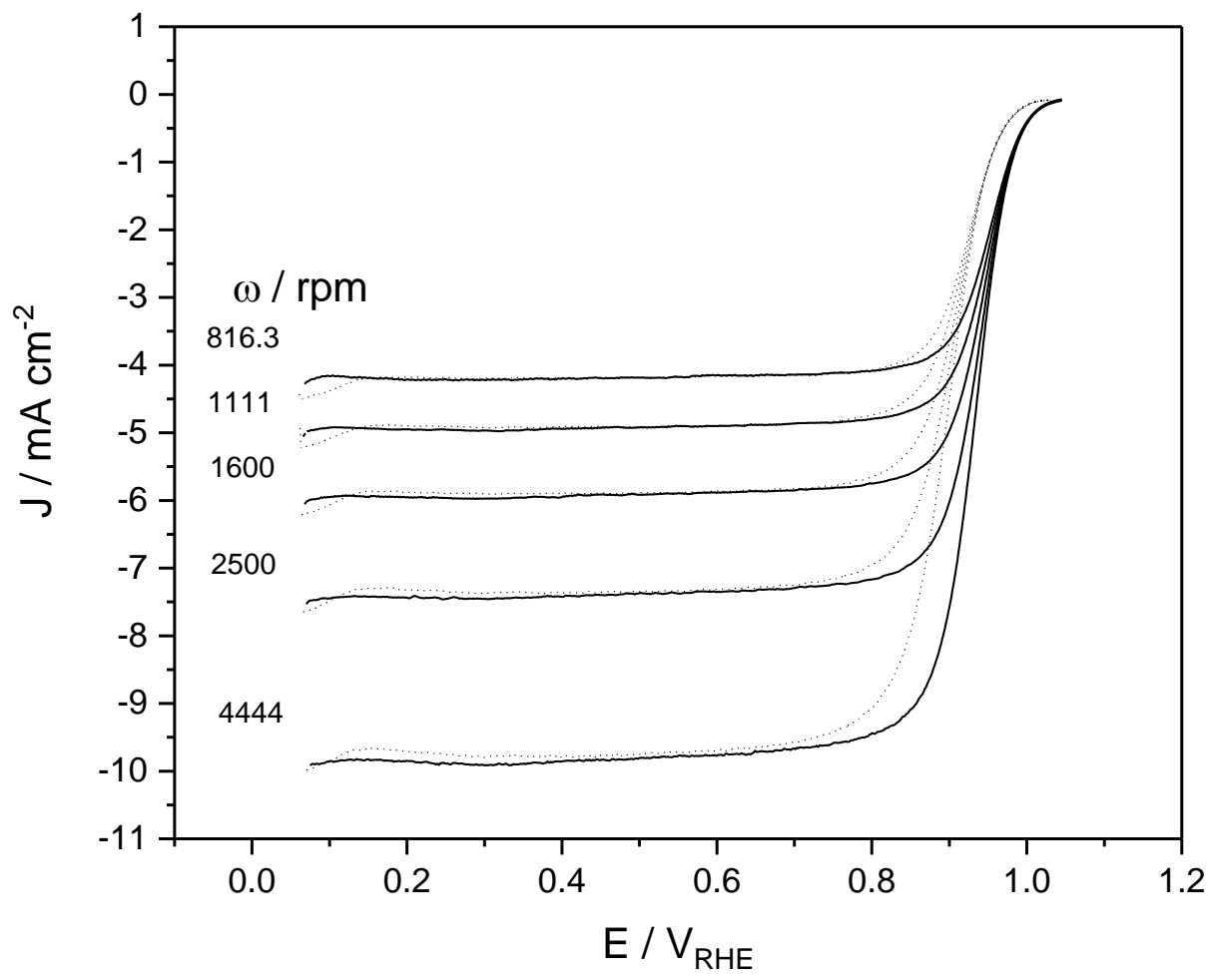




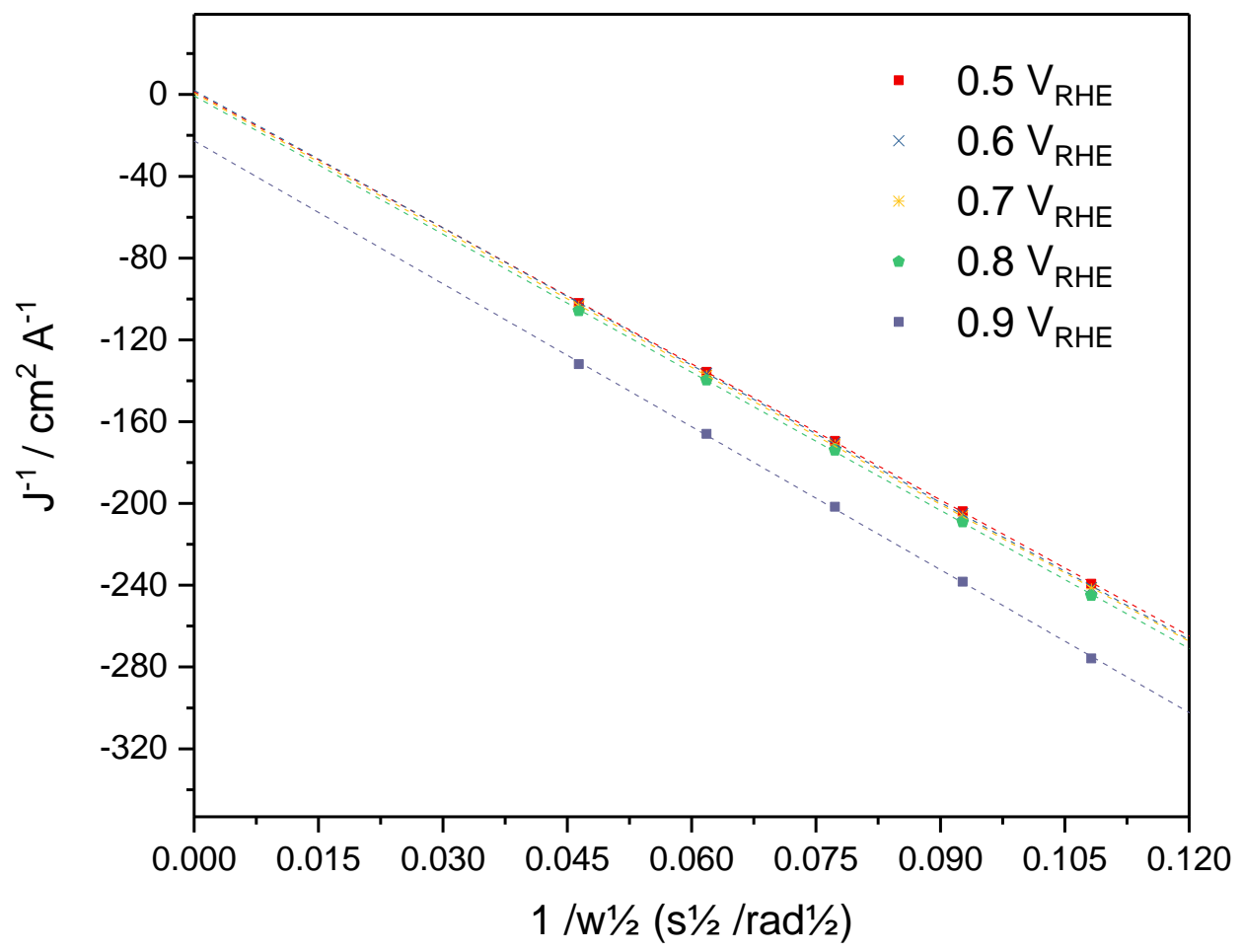

(B)

Figure 5: (A) Oxygen Reduction Reaction polarization curves of $\mathrm{Pt}_{2} \mathrm{Cu}_{98}$ recorded by $\mathrm{RDE}$ in $0.1 \mathrm{M} \mathrm{HClO}_{4}$ electrolyte using a scan rate of $100 \mathrm{mV} \mathrm{s}^{-1}$ and rotation rates of $816.3,1111,1600,2500$ and $4444 \mathrm{rpm}$ corrected for capacitive background and internal resistance. The measurements are recorded at room temperature. (B) The corresponding Koutecky-Levich analysis.
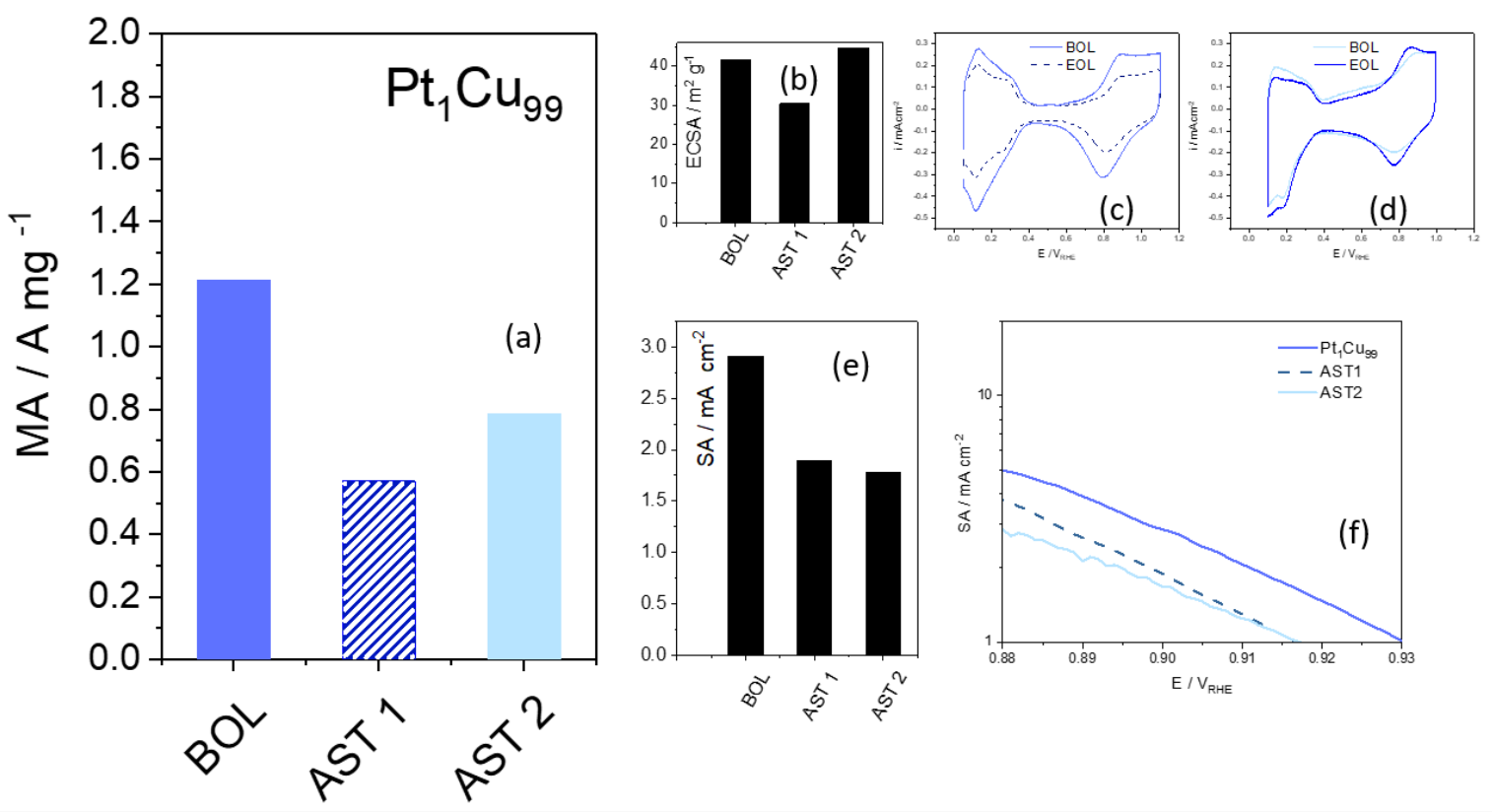
Figure 6. Degradation of nanostructured $\mathrm{Pt}-\mathrm{Cu}\left(\mathrm{Pt}_{1} \mathrm{Cu}_{99}\right)$ determined by accelerated stress testing (AST) with protocol AST 1 (10000 potential steps for $3 \mathrm{~s}$ between $0.6 \mathrm{~V}_{\text {RHE }}$ and $1 \mathrm{~V}_{\mathrm{RHE}}$ ) and protocol AST 2 ( 27000 cycles at $500 \mathrm{mV} \mathrm{s}^{-1}, 1 \mathrm{~V}_{\mathrm{RHE}}-1.5 \mathrm{~V}_{\mathrm{RHE}}$ ): (a) Mass activity beginning of life (BOL), after accelerated stress test 1 (AST 1) and after accelerated stress test 2(AST 2); (b) ECSA at BOL and after AST 1 and AST 2; (c) Cyclic voltammogram in Argon before (BOL) and after (EOL) AST 1; (d) Cyclic voltammogram in Ar saturated $0.1 \mathrm{M} \mathrm{HClO}_{4}$ before (BOL) and after (EOL) AST 2; (e) Specific Activity beginning of life and after AST 1 and AST 2; (f) Tafel plot of $\mathrm{Pt}_{1} \mathrm{Cu}_{99}$ at the beginning of life and after AST1 and AST 2. The MA and the ECSA EOL are calculated with the final Pt loading after AST.
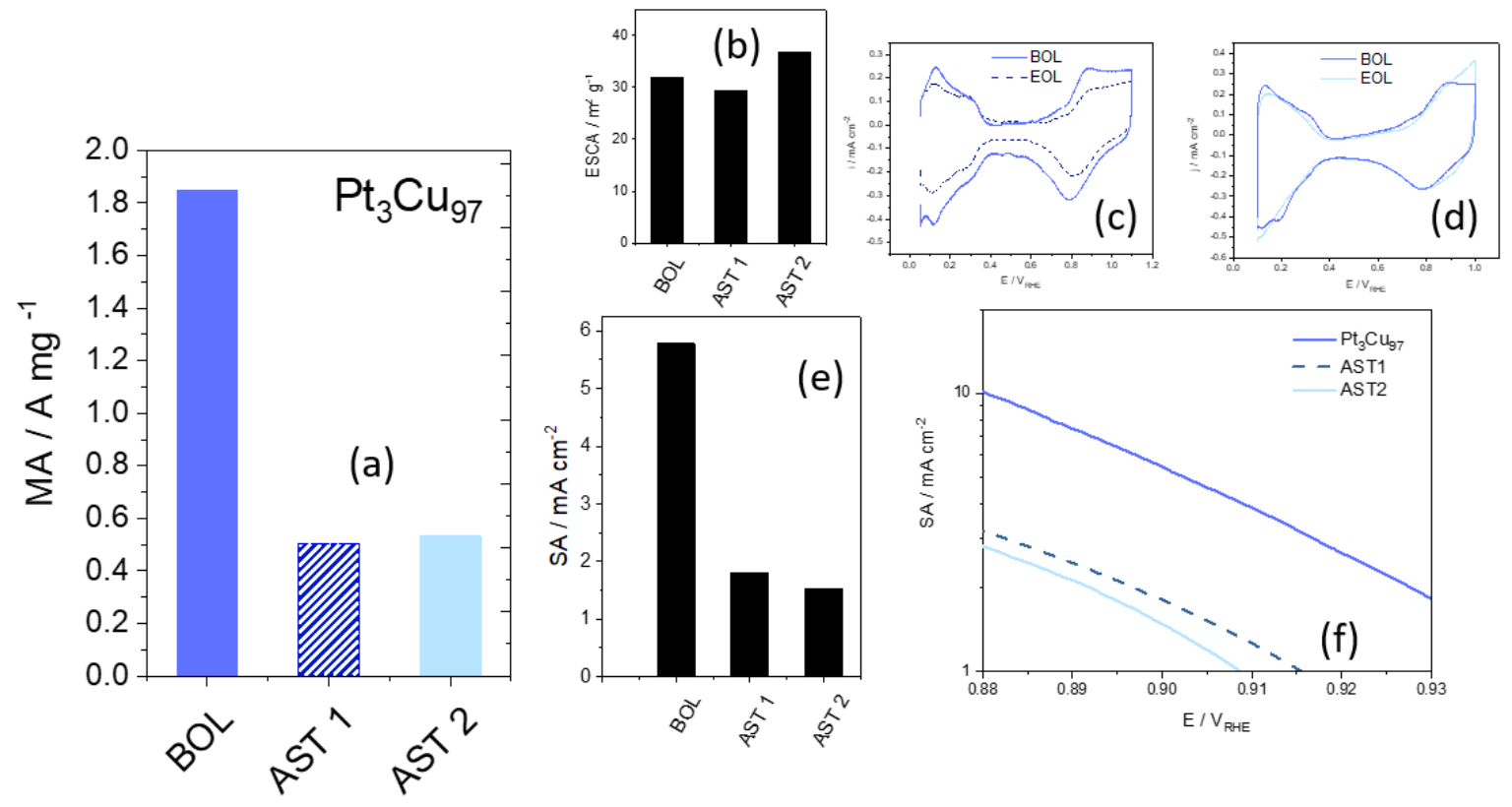

Figure 7: Degradation of nanostructured $\mathrm{Pt}-\mathrm{Cu}\left(\mathrm{Pt}_{3} \mathrm{Cu}_{97}\right)$ determined by accelerated stress testing (AST) with protocol AST 1 (10000 potential steps for $3 \mathrm{~s}$ between $0.6 \mathrm{~V}_{\mathrm{RHE}}$ and $1 \mathrm{~V}_{\mathrm{RHE}}$ ) and protocol AST 2 ( 27000 cycles at $500 \mathrm{mV} \mathrm{s}^{-1}, 1 \mathrm{~V}_{\mathrm{RHE}}-1.5 \mathrm{~V}_{\mathrm{RHE}}$ ): (a) Mass activity beginning of life (BOL), after accelerated stress test 1 (AST 1) and after accelerated stress test 2 (AST 2); (b) ECSA at BOL and after AST 1 and AST 2; (c) Cyclic voltammogram in Argon before (BOL) and after (EOL) AST 1; (d) Cyclic voltammogram in Ar saturated $0.1 \mathrm{M} \mathrm{HClO}_{4}$ before (BOL) and after (EOL) AST 2; (e) Specific Activity beginning of life and after AST 1 and AST 2; (f) Tafel plot of $\mathrm{Pt}_{3} \mathrm{Cu}_{97}$ at the beginning of life and after AST1 and AST 2. The MA and the ECSA EOL are calculated with the final Pt loading after AST.
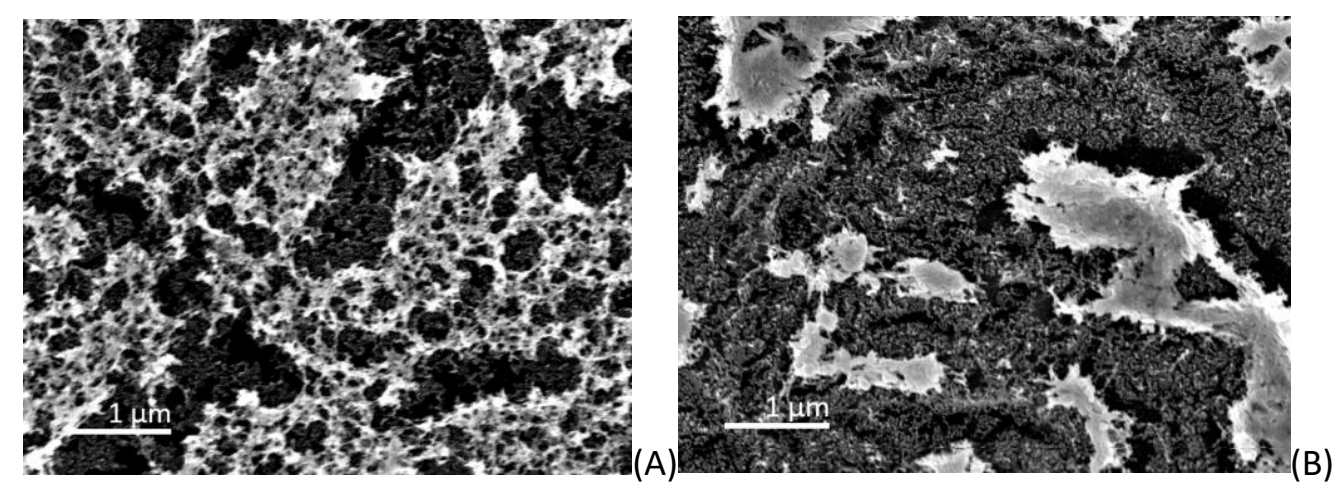

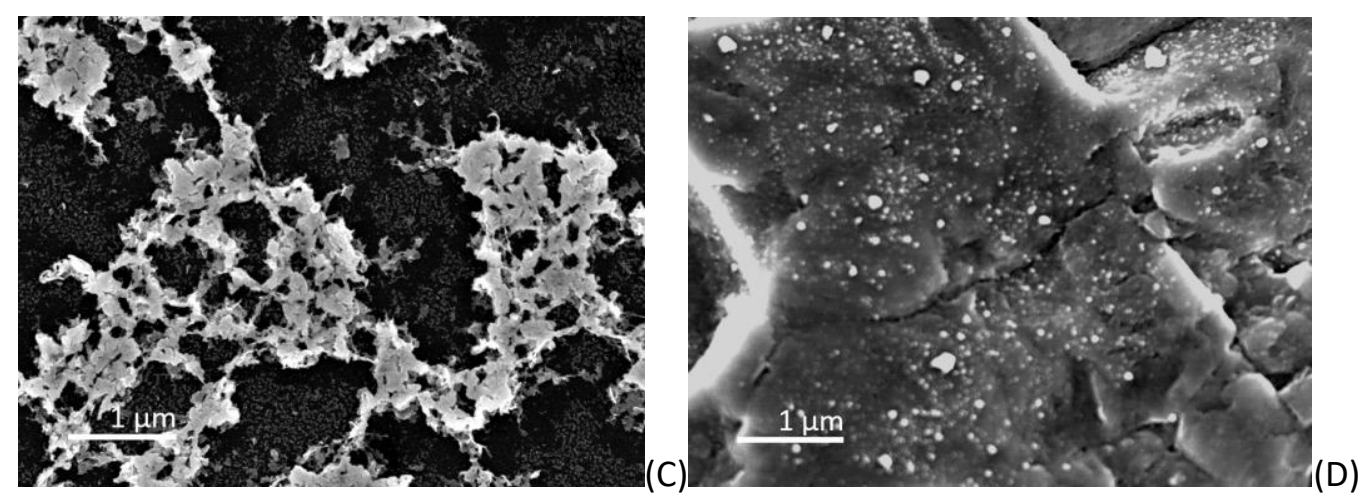

Figure 8: SEM Micrograph measured at $5 \mathrm{kV}$ with the SEl detector $(\mathrm{A}) \mathrm{Pt}_{1} \mathrm{Cu}_{99}$ after degradation with AST 2, (B) $\mathrm{Pt}_{1} \mathrm{Cu}_{99}$ after degradation with AST 1, (C) $\mathrm{Pt}_{3} \mathrm{Cu}_{97}$ after degradation with AST 2 and (D) $\mathrm{Pt}_{3} \mathrm{Cu}_{97}$ after degradation with AST 1

Table 3: EDS results, Specific Activitiy, Mass Activity and Pt loading after accelerated stress testing of the samples $\mathrm{Pt}_{3} \mathrm{Cu}_{97}$ and $\mathrm{Pt}_{1} \mathrm{Cu}_{99}$

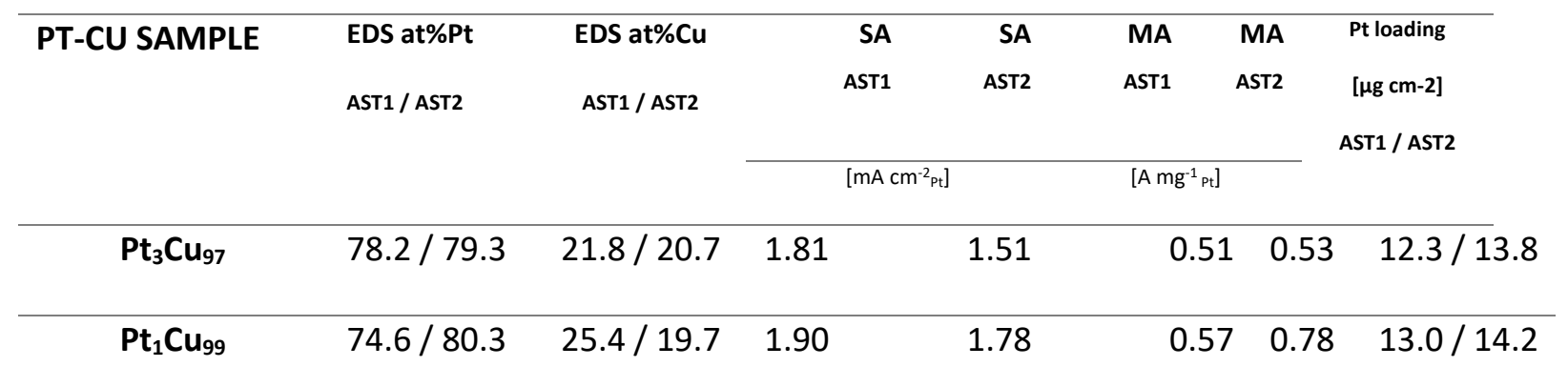

SA: Specific Activity @0.9 $\mathrm{V}_{\mathrm{RHE}}$ in $0.1 \mathrm{M} \mathrm{HClO}_{4}$; MA: Mass Activity @0.9 $\mathrm{V}_{\mathrm{RHE}}$ in $0.1 \mathrm{M} \mathrm{HClO}_{4}$. The mass activity was calculated with the final loading after accelerated stress testing. 
[1] J.K. Nørskov, J. Rossmeisl, A. Logadottir, L. Lindqvist, J.R. Kitchin, T. Bligaard, H. Jónsson, Origin of the overpotential for oxygen reduction at a fuel-cell cathode, J. Phys. Chem. B. 108 (2004) 17886-17892. doi:10.1021/jp047349j.

[2] I. Spanos, J.J.K. Kirkensgaard, K. Mortensen, M. Arenz, Investigating the activity enhancement on PtxCo1-x alloys induced by a combined strain and ligand effect, J. Power Sources. 245 (2014) 908-914. doi:10.1016/j.jpowsour.2013.07.023.

[3] Y.J. Deng, V. Tripkovic, J. Rossmeisl, M. Arenz, Oxygen Reduction Reaction on Pt Overlayers Deposited onto a Gold Film: Ligand, Strain, and Ensemble Effect, ACS Catal. 6 (2016) 671-676. doi:10.1021/acscatal.5b02409.

[4] K. Kinoshita, Particle Size Effects for Oxygen Reduction on Highly Dispersed Platinum in Acid Electrolytes, J. Electrochem. Soc. 137 (1990) 845-848. doi:10.1149/1.2086566.

[5] M. Nesselberger, S. Ashton, J.C. Meier, I. Katsounaros, K.J.J.J. Mayrhofer, M. Arenz, The particle size effect on the oxygen reduction reaction activity of Pt catalysts: influence of electrolyte and relation to single crystal models., J. Am. Chem. Soc. 133 (2011) 17428-33. doi:10.1021/ja207016u.

[6] H.A. Gasteiger, S.S. Kocha, B. Sompalli, F.T. Wagner, Activity benchmarks and requirements for Pt, Pt-alloy, and non-Pt oxygen reduction catalysts for PEMFCs, Appl. Catal. B Environ. 56 (2005) 9-35. doi:10.1016/j.apcatb.2004.06.021.

[7] M. Arenz, A. Zana, Fuel cell catalyst degradation: Identical location electron microscopy and related methods, Nano Energy. 29 (2016) 299-313. doi:10.1016/j.nanoen.2016.04.027.

[8] A. Sarapuu, A. Kasikov, T. Laaksonen, K. Kontturi, K. Tammeveski, Electrochemical reduction of oxygen on thin-film Pt electrodes in acid solutions, Electrochim. Acta. 53 (2008) 5873-5880. doi:10.1016/j.electacta.2008.04.003.

[9] N. Menzel, E. Ortel, R. Kraehnert, P. Strasser, Electrocatalysis using porous nanostructured materials, ChemPhysChem. 13 (2012) 1385-94. doi:10.1002/cphc.201100984.

[10] J. Erlebacher, M.J. Aziz, a Karma, N. Dimitrov, K. Sieradzki, Evolution of nanoporosity in dealloying., Nature. 410 (2001) 450-453. doi:10.1038/35068529.

[11] A.A. El Mel, F. Boukli-Hacene, L. Molina-Luna, N. Bouts, A. Chauvin, D. Thiry, E. Gautron, N. Gautier, P.Y. Tessier, Unusual dealloying effect in gold/copper alloy thin films: The role of defects and column boundaries in the formation of nanoporous gold, ACS Appl. Mater. Interfaces. 7 (2015) 2310-2321. doi:10.1021/am5065816.

[12] D.F. van der Vliet, C. Wang, D. Tripkovic, D. Strmcnik, X.F. Zhang, M.K. Debe, R.T. Atanasoski, N.M. Markovic, V.R. Stamenkovic, Mesostructured thin films as electrocatalysts with tunable composition and surface morphology., Nat. Mater. 11 (2012) 1051-8. doi:10.1038/nmat3457.

[13] G. Sievers, S. Mueller, A. Quade, F. Steffen, S. Jakubith, A. Kruth, V. Brueser, Mesoporous Pt-Co oxygen reduction reaction (ORR) catalysts for low temperature proton exchange membrane fuel cell synthesized by alternating sputtering, J. Power Sources. 268 (2014) 255-260. doi:10.1016/j.jpowsour.2014.06.013.

[14] M. Li, M. Li, Z. Zhao, T. Cheng, A. Fortunelli, C. Chen, R. Yu, L. Gu, B. Merinov, Z. Lin, E. Zhu, T. Yu, Q. Jia, J. Guo, L. Zhang, W.A.G. lii, Y. Huang, X. Duan, Ultrafine jagged platinum nanowires enable ultrahigh mass activity for the oxygen reduction reaction, Science (80-. ). 354 (2016) 1414. doi:10.1126/science.aaf9050. 
[15] C. Chen, Y. Kang, Z. Huo, Z. Zhu, W. Huang, H.L. Xin, J.D. Snyder, D. Li, J. a Herron, M. Mavrikakis, M. Chi, K.L. More, Y. Li, N.M. Markovic, G.A. Somorjai, P. Yang, V.R. Stamenkovic, Highly crystalline multimetallic nanoframes with three-dimensional electrocatalytic surfaces., Science. 343 (2014) 1339-43. doi:10.1126/science.1249061.

[16] K. Tammeveski, M. Arulepp, T. Tenno, C. Ferrater, J. Claret, Oxygen electroreduction on titanium-supported thin Pt films in alkaline solution, Electrochim. Acta. 42 (1997) 2961-2967. doi:10.1016/s0013-4686(97)00119-9.

[17] K.J.J. Mayrhofer, S.J. Ashton, J. Kreuzer, M. Arenz, An electrochemical cell configuration incorporating an ion conducting membrane separator between reference and working electrode, Int. J. Electrochem. Sci. 4 (2009) 1-8.

[18] K. Mayrhofer, D. Strmcnik, B.B. Blizanac, V. Stamenkovic, M. Arenz, N.M. Markovic, Measurement of oxygen reduction activities via the rotating disc electrode method: From Pt model surfaces to carbon-supported high surface area catalysts, Electrochim. Acta. 53 (2008) 3181-3188. doi:10.1016/j.electacta.2007.11.057.

[19] A. Zana, G.K.H. Wiberg, Y.J. Deng, T. Østergaard, J. Rossmeisl, M. Arenz, Accessing the Inaccessible: Analyzing the Oxygen Reduction Reaction in the Diffusion Limit, ACS Appl. Mater. Interfaces. 9 (2017) 38176-38180. doi:10.1021/acsami.7b13902.

[20] J. Speder, A. Zana, I. Spanos, J.J.K. Kirkensgaard, K. Mortensen, M. Arenz, On the influence of the Pt to carbon ratio on the degradation of high surface area carbon supported PEM fuel cell electrocatalysts, Electrochem. Commun. $34 \quad$ (2013) 153-156. doi:10.1016/j.elecom.2013.06.001.

[21] A. Ohma, K. Shinohara, A. liyama, T. Yoshida, Membrane and Catalyst Performance Targets for Automotive Fuel Cells by FCCJ Membrane, Catalyst, MEA WG, ECS Trans. 41 (2011) 775-784. doi:10.1149/1.3635611.

[22] H.J. Qiu, X. Shen, J.Q. Wang, A. Hirata, T. Fujita, Y. Wang, M.W. Chen, Aligned nanoporous Pt$\mathrm{Cu}$ bimetallic microwires with high catalytic activity toward methanol electrooxidation, ACS Catal. 5 (2015) 3779-3785. doi:10.1021/acscatal.5b00073.

[23] D.M. Mattox, Atomistic Film Growth and Some Growth-Related Film Properties, Elsevier, 2010. doi:10.1016/B978-0-8155-2037-5.00010-1.

[24] M. Oezaslan, P. Strasser, Activity of dealloyed PtCo3 and PtCu3 nanoparticle electrocatalyst for oxygen reduction reaction in polymer electrolyte membrane fuel cell, J. Power Sources. 196 (2011) 5240-5249. doi:10.1016/j.jpowsour.2010.11.016.

[25] N. Hodnik, C. Jeyabharathi, J.C. Meier, A. Kostka, K.L. Phani, A. Rečnik, M. Bele, S. Hočevar, M. Gaberšček, K.J.J. Mayrhofer, Effect of ordering of $\mathrm{PtCu}{ }_{3}$ nanoparticle structure on the activity and stability for the oxygen reduction reaction, Phys. Chem. Chem. Phys. 16 (2014) 1361013615. doi:10.1039/C4CP00585F.

[26] N. Hodnik, C. Baldizzone, S. Cherevko, A. Zeradjanin, K.J.J. Mayrhofer, The Effect of the Voltage Scan Rate on the Determination of the Oxygen Reduction Activity of Pt/C Fuel Cell Catalyst, Electrocatalysis. 6 (2015) 237-241. doi:10.1007/s12678-015-0255-0.

[27] P. Strasser, S. Koh, T. Anniyev, J. Greeley, K. More, C. Yu, Z. Liu, S. Kaya, D. Nordlund, H. Ogasawara, M.F. Toney, A. Nilsson, Lattice-strain control of the activity in dealloyed core-shell fuel cell catalysts, Nat. Chem. 2 (2010) 454-460. doi:10.1038/nchem.623.

[28] E. Fabbri, A. Rabis, R. Kotz, T.J. Schmidt, Pt nanoparticles supported on Sb-doped SnO2 porous structures: developments and issues, Phys. Chem. Chem. Phys. 16 (2014) 13672-13681. doi:10.1039/C4CP00238E. 
[29] A. Topalov, I. Katsounaros, M. Auinger, S. Cherevko, J.C. Meier, S.O. Klemm, K.J.J. Mayrhofer, Dissolution of platinum: Limits for the deployment of electrochemical energy conversion?, Angew. Chemie - Int. Ed. 51 (2012) 12613-12615. doi:10.1002/anie.201207256.

[30] A. Zana, J. Speder, N.E.A. Reeler, T. Vosch, M. Arenz, Investigating the corrosion of high surface area carbons during start/stop fuel cell conditions: A Raman study, Electrochim. Acta. 114 (2013) 455-461. doi:10.1016/j.electacta.2013.10.097.

[31] J. Speder, A. Zana, I. Spanos, J.J.K. Kirkensgaard, K. Mortensen, M. Hanzlik, M. Arenz, Comparative degradation study of carbon supported proton exchange membrane fuel cell electrocatalysts - The influence of the platinum to carbon ratio on the degradation rate, J. Power Sources. 261 (2014) 14-22. doi:10.1016/j.jpowsour.2014.03.039.

[32] S. Chen, H.A. Gasteiger, K. Hayakawa, T. Tada, Y. Shao-Horn, Platinum-Alloy Cathode Catalyst Degradation in Proton Exchange Membrane Fuel Cells: Nanometer-Scale Compositional and Morphological Changes, J. Electrochem. Soc. 157 (2010) A82. doi:10.1149/1.3258275.

[33] R. Yang, J. Leisch, P. Strasser, M.F. Toney, Structure of dealloyed PtCu3 thin films and catalytic activity for oxygen reduction, Chem. Mater. 22 (2010) 4712-4720. doi:10.1021/cm101090p. 


\section{Supporting Information}

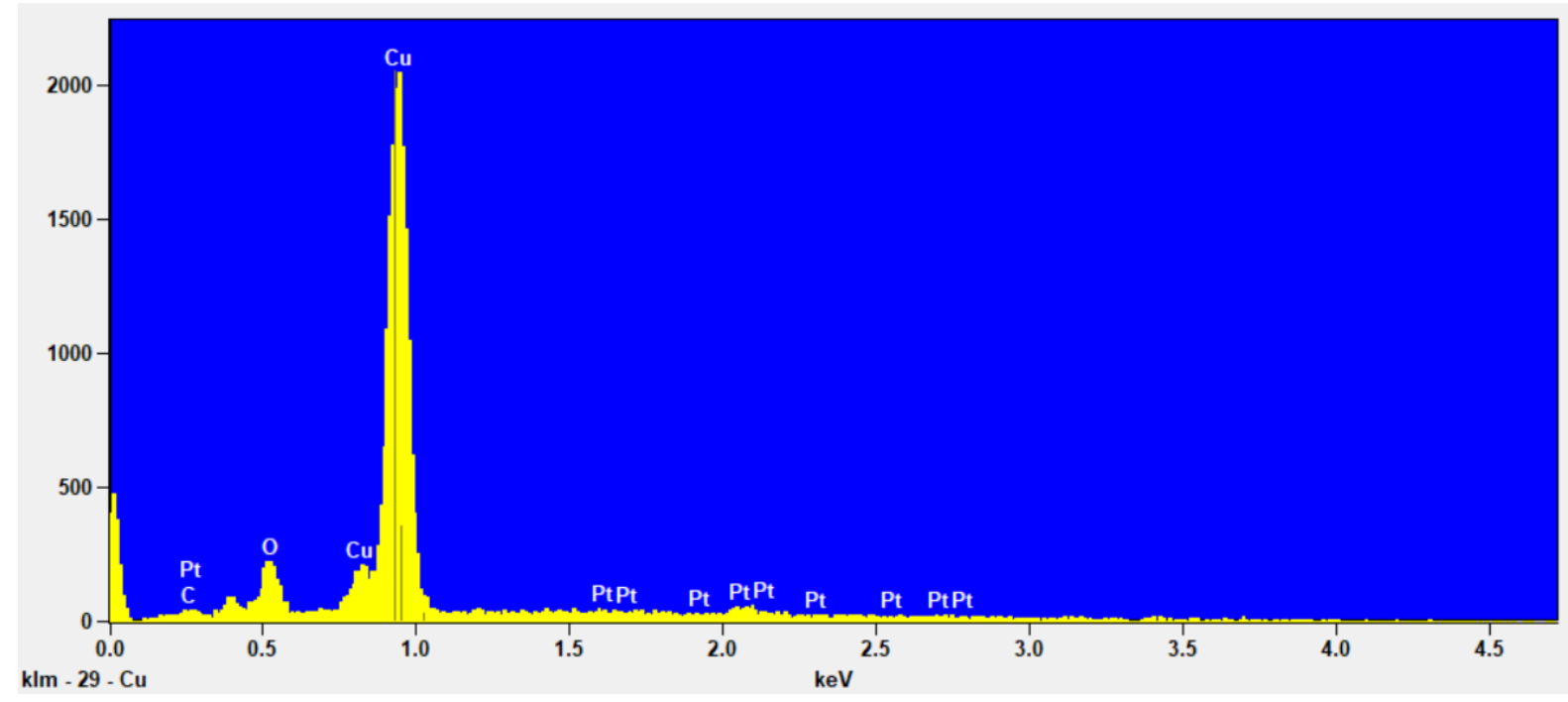

(A)

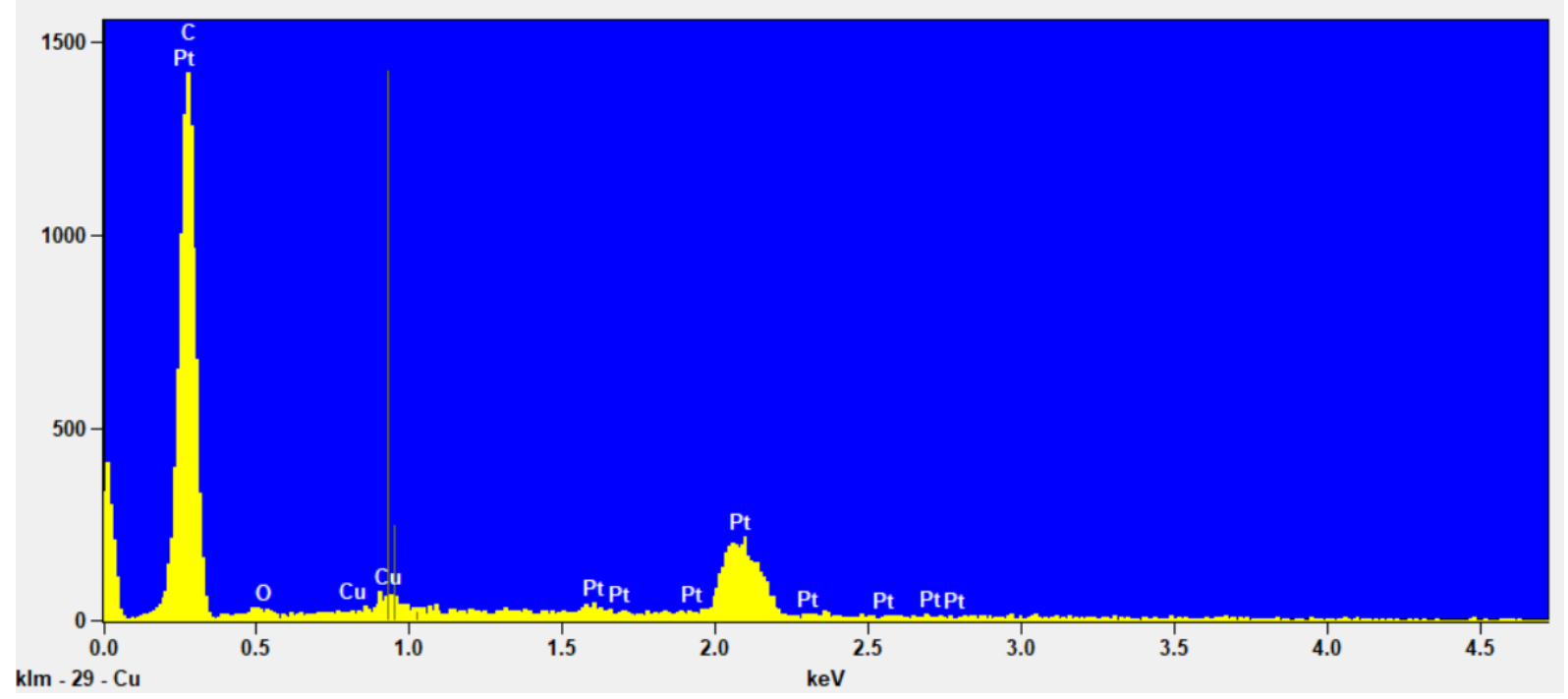

(B)

Figure S 1: Representative EDS Spectra of (A) an as synthesized $\mathrm{Pt}_{2} \mathrm{Cu}_{98}$ template and (B) a leached $\mathrm{Pt}_{2} \mathrm{Cu}_{98}$ network. 


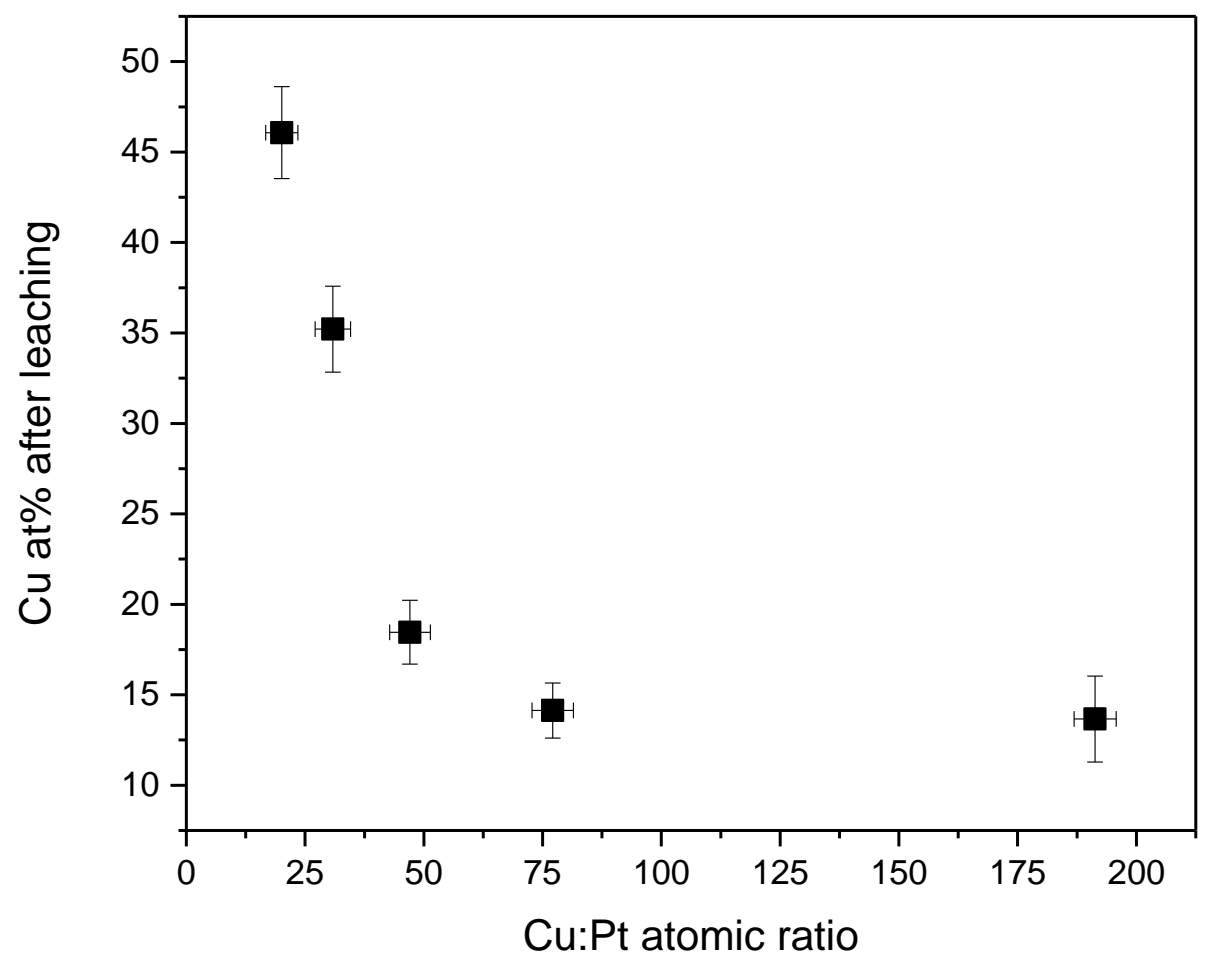

Figure S 2: Atomic Ratio of $\mathrm{Cu}: \mathrm{Pt}$ in as deposited template in correlation to the $\mathrm{Cu}$ at\% in the leached Pt-Cu networks as determined by EDS. 


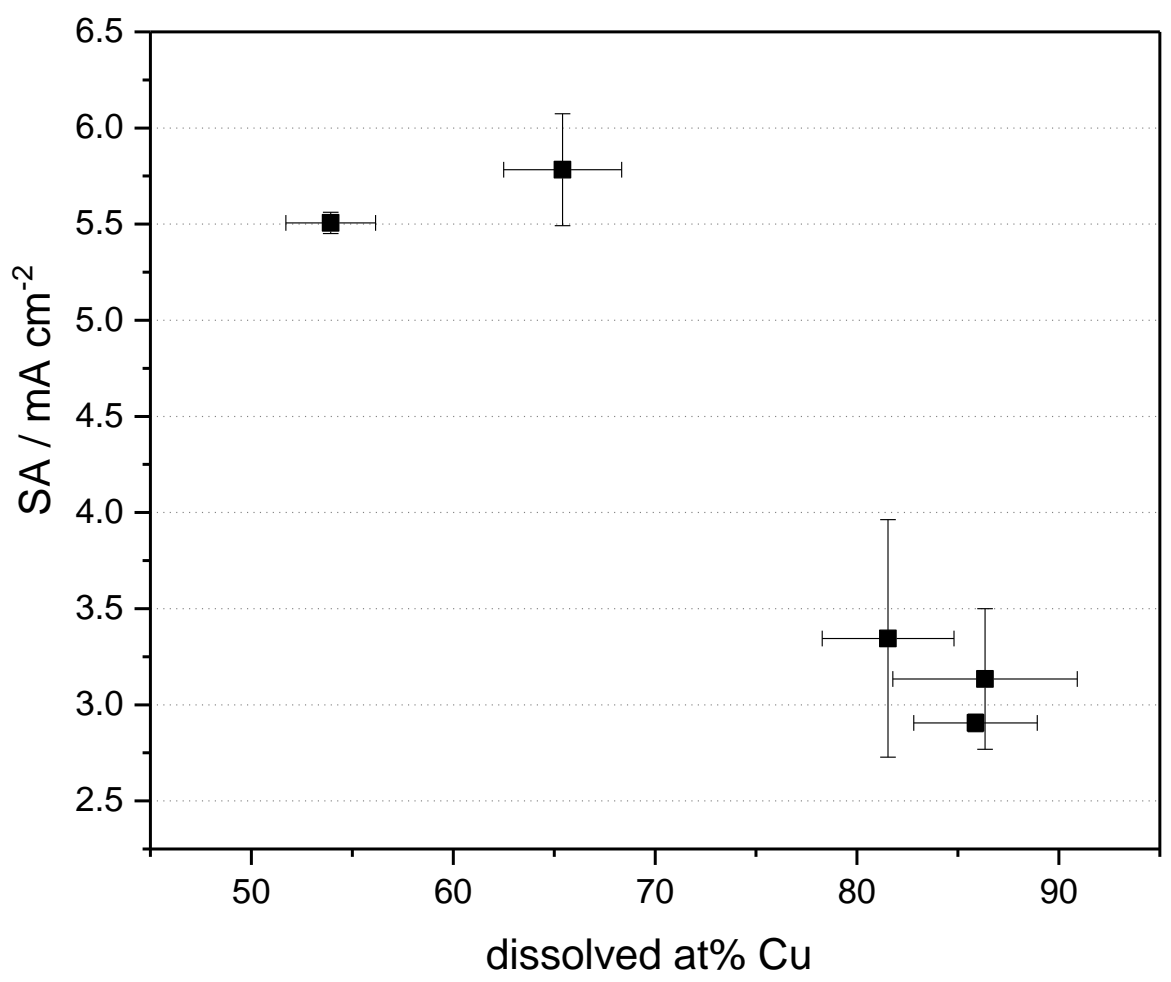

Figure S 3: Specific ORR activity of nanostructured Pt-Cu determined by RDE in $0.1 \mathrm{M} \mathrm{HClO}_{4}$ electrolyte using a rotation rate of $1600 \mathrm{rpm}$ and a scan rate $50 \mathrm{mV} \mathrm{s}^{-1}$ at room temperature in relation to the dissolved Cu content after orr as measured by EDS. 

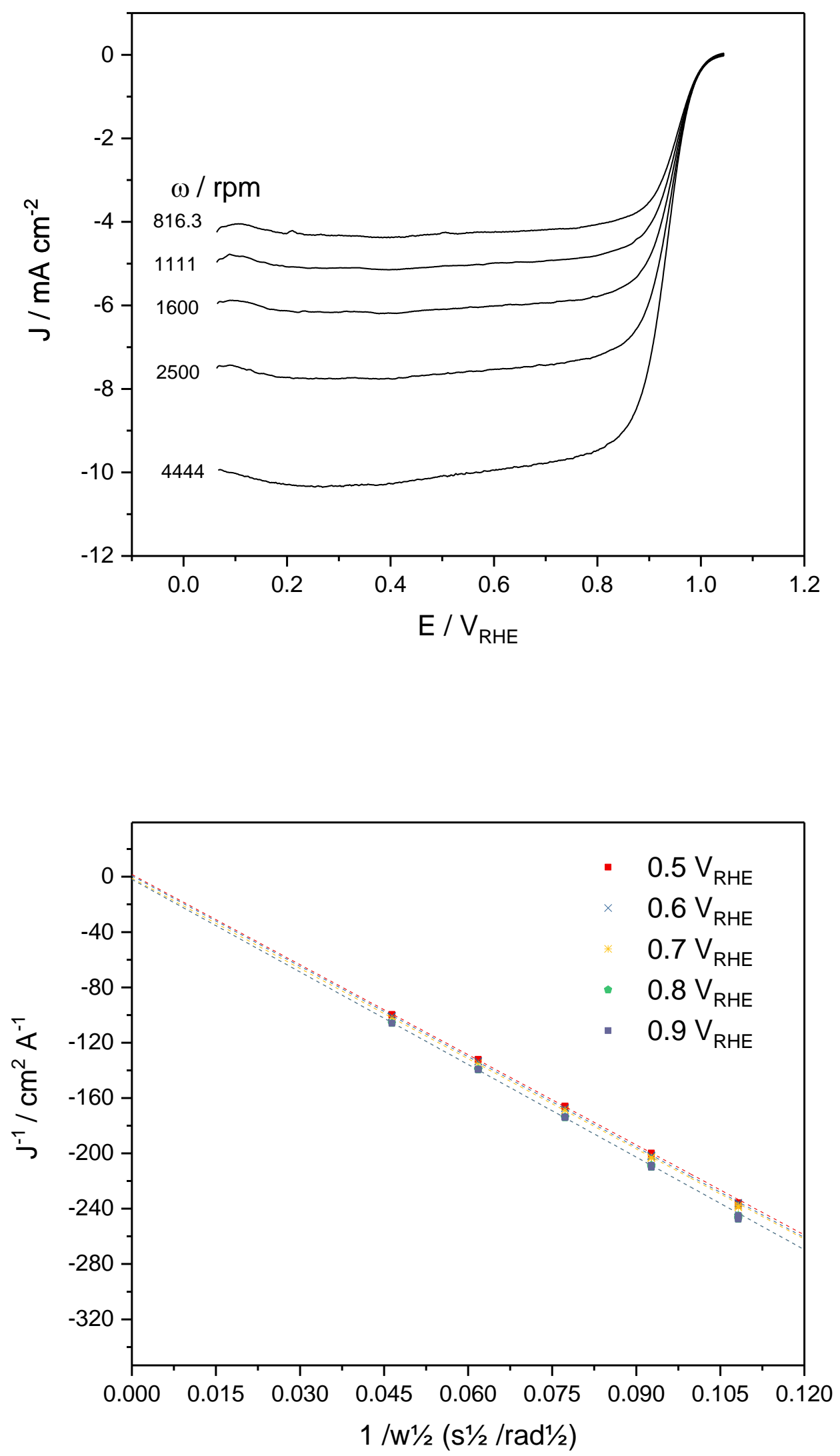

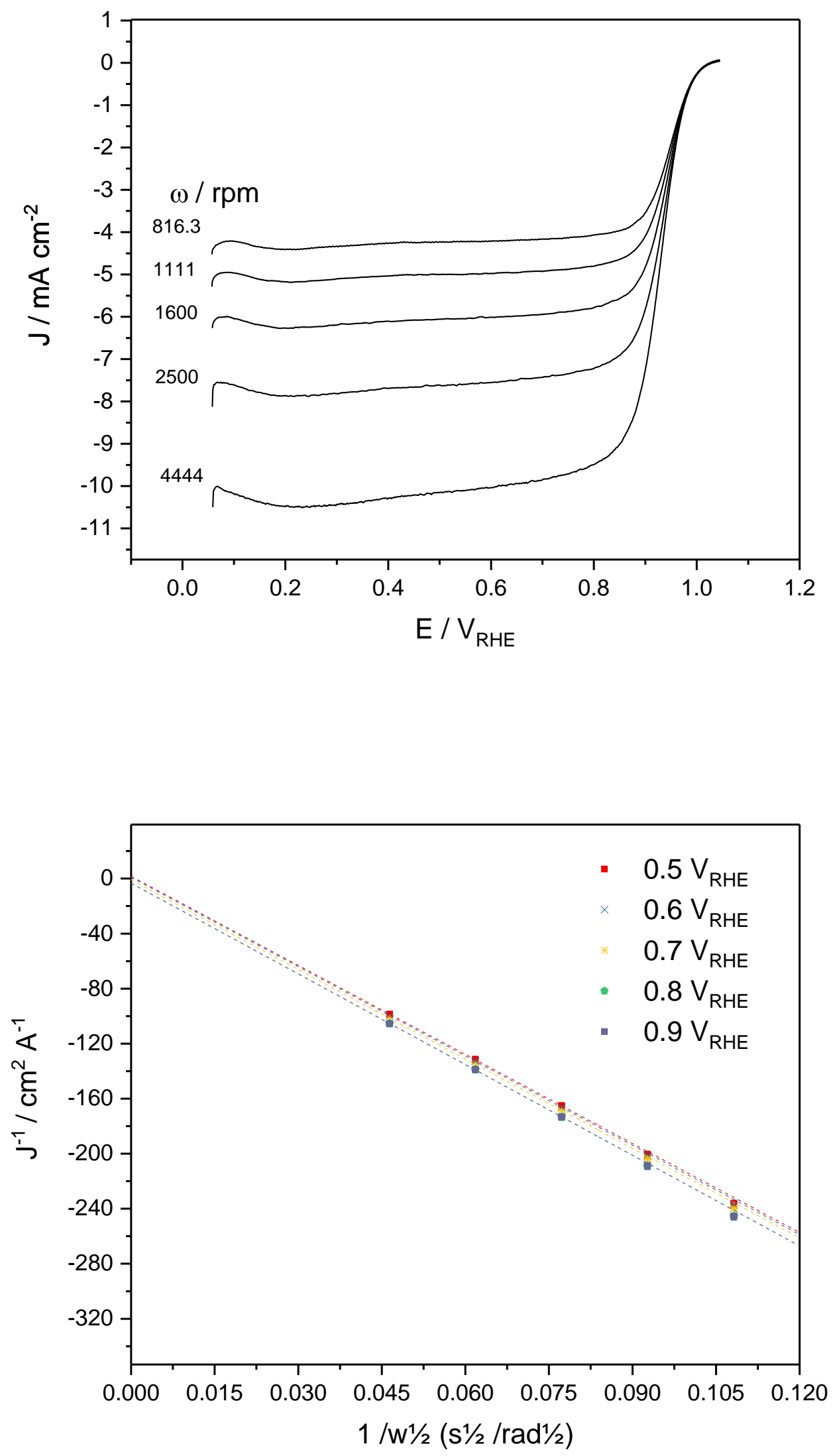

(B) 

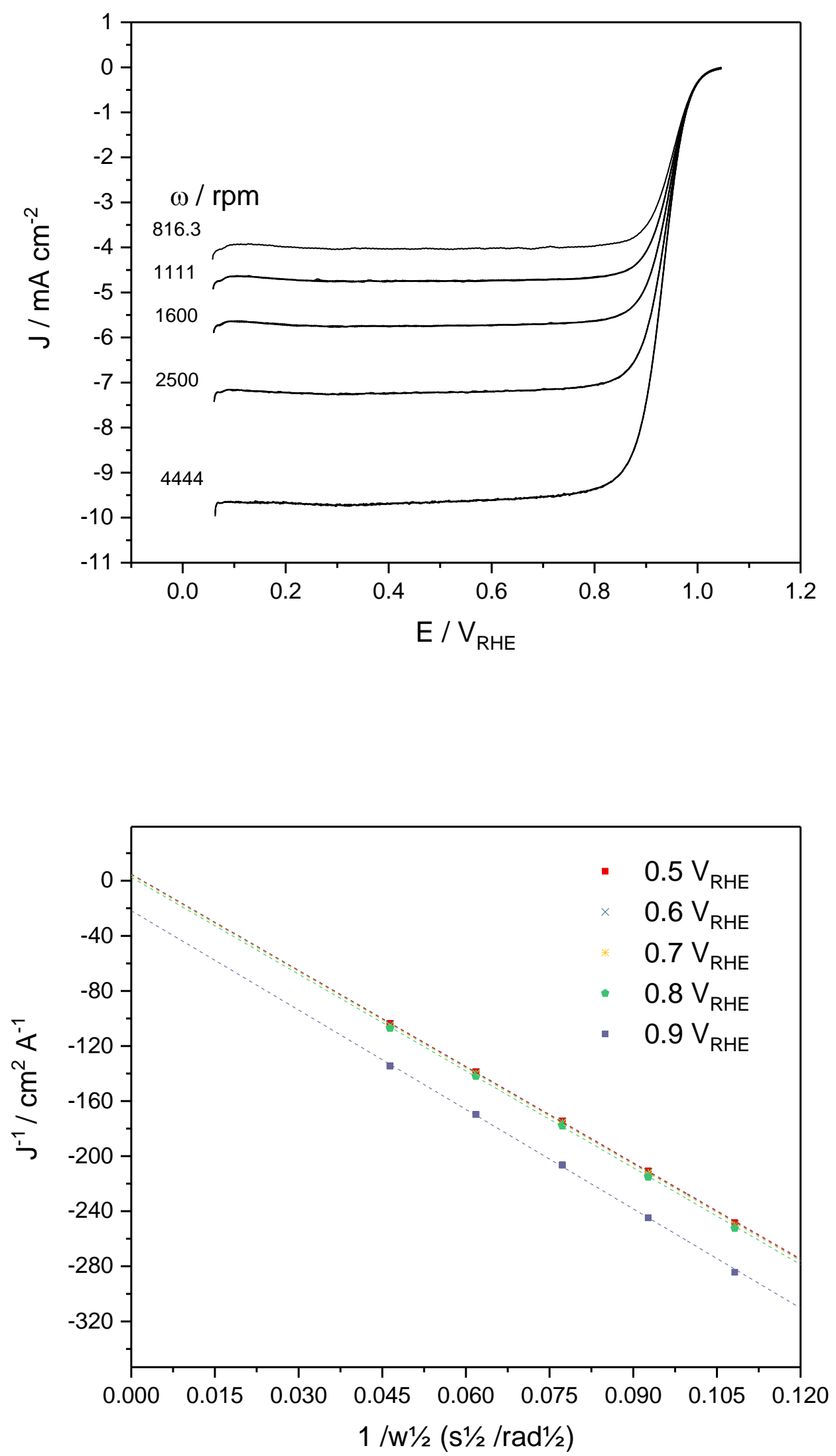

(C) 

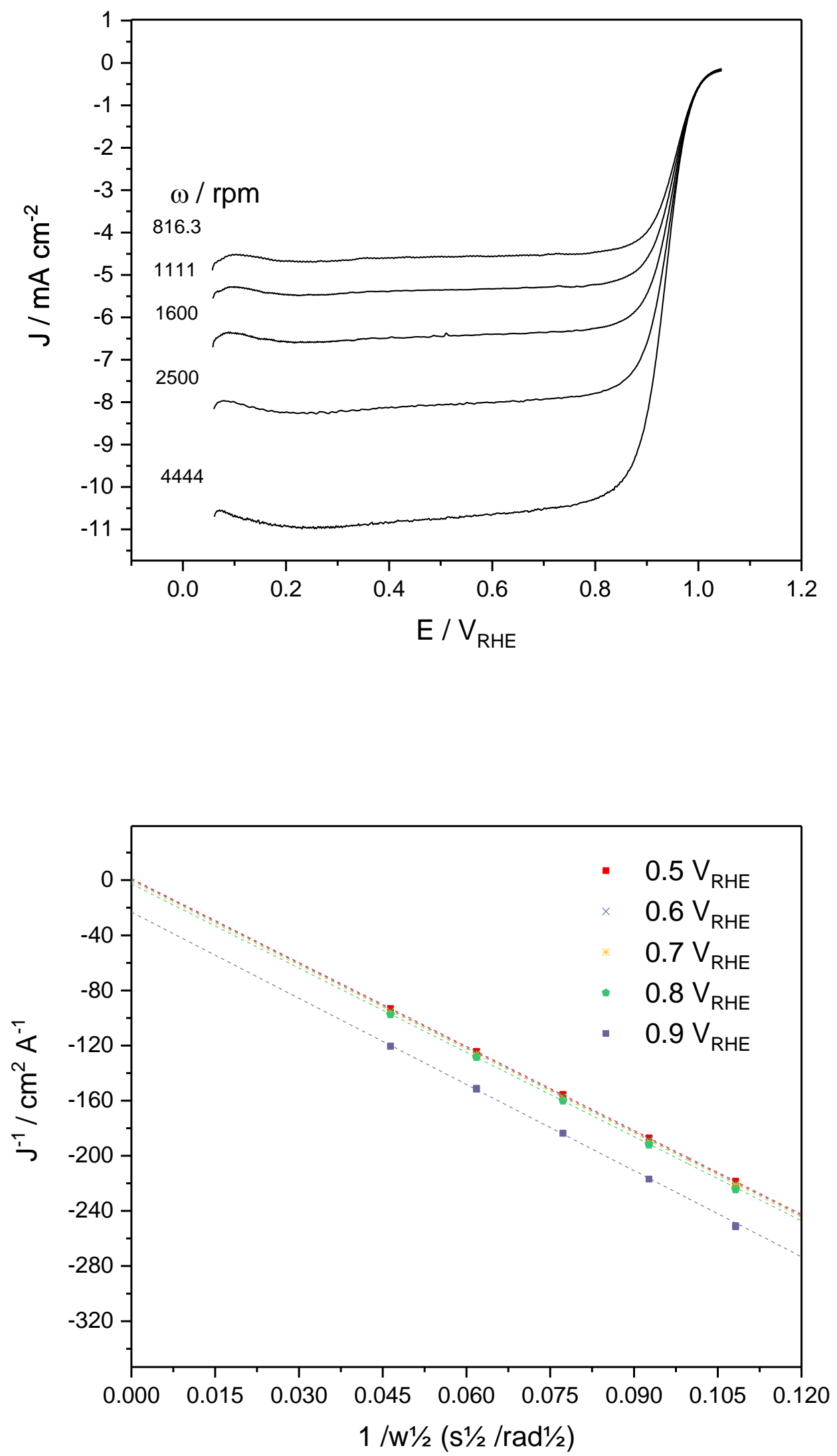

(D) 
Figure S 4: Oxygen reduction polarization curves and corresponding Koutecky-Levich Analysis recorded by RDE in $0.1 \mathrm{M} \mathrm{HClO}_{4}$ electrolyte corrected for capacitive background and internal resistance applying different rotation rates and the corresponding Koutecky-Levich analyses. The measurements were conducted at room temperature using a scan rate $100 \mathrm{mV} \mathrm{s}^{-1}$. (A) $\mathrm{Pt}_{0.5} \mathrm{Cu}_{99.5}$ (B) $\mathrm{Pt}_{1} \mathrm{Cu}_{99}$, (C) $\mathrm{Pt}_{3} \mathrm{Cu}_{97}$ and (D) $\mathrm{Pt}_{5} \mathrm{Cu}_{95}$

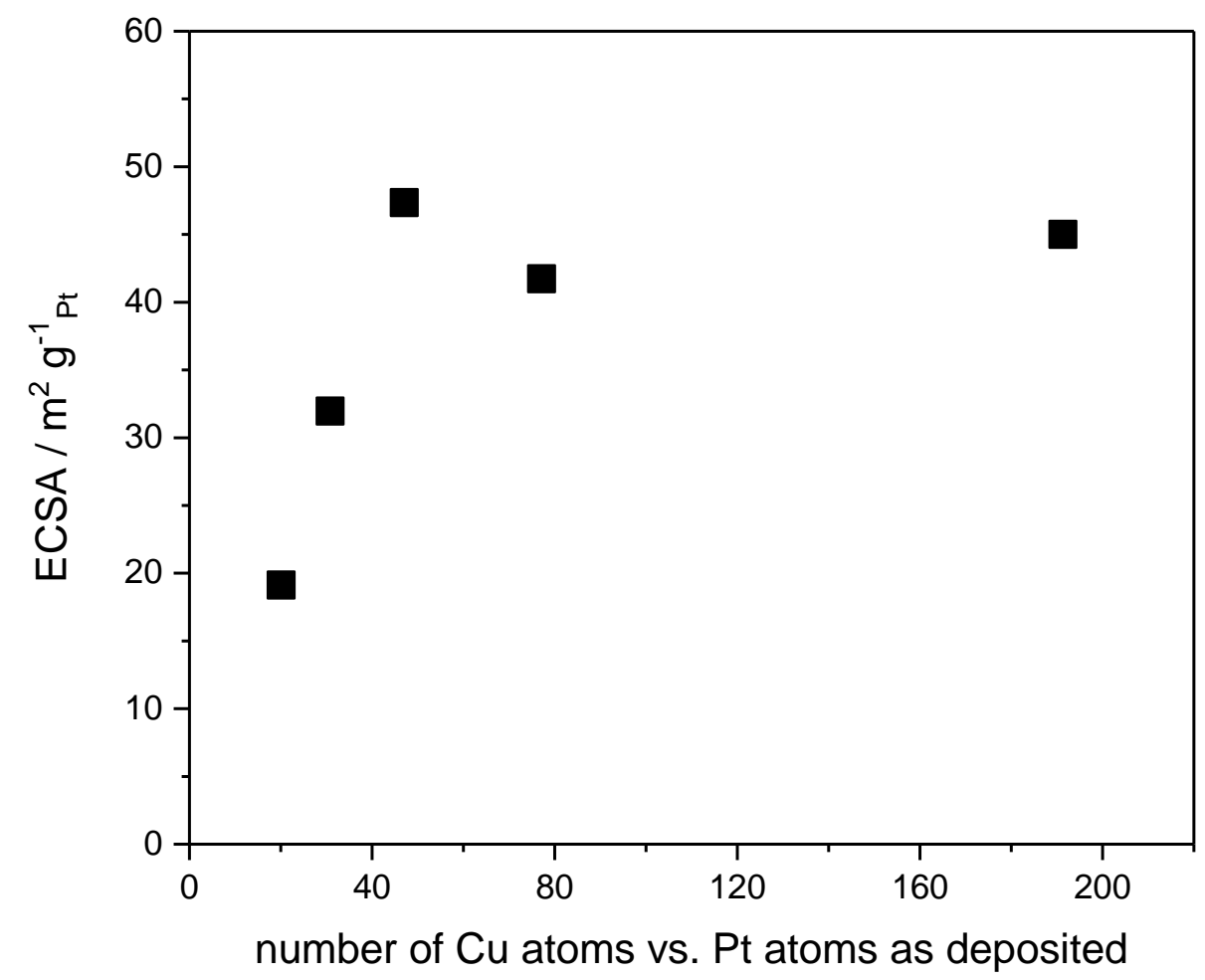

Figure S 3: Electrochemical Surface Area as measured by electrochemical $\mathrm{CO}$ adsorption and oxidation in relation to the initial $\mathrm{Cu}: \mathrm{Pt}$ atomic ratio measured by EDS. 